\title{
Recent progresses of micro-nanostructured transition metal compound-based electrocatalysts for energy conversion technologies
}

\author{
Jiajun Wang ${ }^{1}$, Zhao Zhang ${ }^{1}$, Jia Ding ${ }^{1}$, Cheng Zhong ${ }^{1}$, Yida Deng ${ }^{1}$, Xiaopeng Han ${ }^{1 *}$ and \\ Wenbin $\mathrm{Hu}^{1,2^{*}}$
}

\begin{abstract}
The rapid consumption of fossil fuels has caused increasingly climatic issues and energy crisis, which leads to the urgent demand for developing sustainable and clean energies. Electrocatalysts play a key role in the development of electrochemical energy conversion and storage devices. Especially, developing efficient and cost-effective catalysts is important for the large-scale application of these devices. Among various electrocatalyst candidates, earth abundant transition metal compound (TMC)-based electrocatalysts are being widely and rapidly studied owing to their high electrocatalytic performances. This paper reviews the recent and representative advances in efficient TMC-based electrocatalysts (i.e., oxides, sulfides, selenides, phosphides, carbides and nitrides) for energy electrocatalytic reactions, including hydrogen evolution reaction (HER), oxygen evolution reaction (OER) and oxygen reduction reaction (ORR). Different compounds with different applications are summarized and the relative mechanisms are also discussed. The strategies for developing earth-abundant and low-cost TMC-based electrocatalysts are introduced. In the end, the current challenges and future perspectives in the development of TMC research are briefly discussed. This review also provides the latest advance and outlines the frontiers in TMC-based electrocatalysts, which should provide inspirations for the further development of low-cost and high-efficiency catalysts for sustainable clean energy technologies.
\end{abstract}

Keywords: energy electrocatalysis, transition metal compounds, HER, OER, ORR

\section{INTRODUCTION}

The rapidly increasing consumption of fossil fuels (e.g., coal, petroleum and natural gas) is causing a series of climatic issues and seriously damaging the global environment [1-3]. Developing renewable and environment-friendly energy systems has shown promising prospects for the sustainable development of human society [4-7]. Among various strategies, the electrochemical energy conversion and storage devices have drawn great attentions due to their low carbon emissions and high energy densities [8]. Typically, these devices with different applications usually involve different electrochemical reactions, such as hydrogen evolution reaction (HER), oxygen evolution reaction (OER), oxygen reduction reaction (ORR), $\mathrm{CO}_{2}$ electroreduction reaction $\left(\mathrm{CO}_{2} \mathrm{RR}\right)$ and alkohol electrooxidation reaction (AOR) [9-12]. Therefore, it is critical to improve the kinetics and reduce the power consumptions of these reactions for high device performances. Electrocatalysts play a critical role in enhancing reaction rates via facilitating the conversion of reaction intermediates and reducing the resistance $[13,14]$. Noble metals have been regarded as the state-ofart electrocatalysts for HER (Pt), OER ( $\mathrm{Ir} / \mathrm{Ru}$ oxide) and ORR (Pt) $[15,16]$. However, the high cost and limited resources still hinder their large-scale commercialization.

Considering the cost and reducing the dependency of noble metals, great efforts have been tried to develop nonprecious metal-based electrocatalysts, such as transition metal-based, transition metal compound (TMC)based and carbon-based nanomaterials $[8,17]$. Especially,

\footnotetext{
${ }^{1}$ School of Materials Science and Engineering, Tianjin Key Laboratory of Composite and Functional Materials, Key Laboratory of Advanced Ceramics and Machining Technology (Ministry of Education), Tianjin University, Tianjin 300072, China

${ }^{2}$ Joint School of National University of Singapore and Tianjin University, International Campus of Tianjin University, Binhai New City, Fuzhou 350207, China

* Corresponding authors (emails: xphan@tju.edu.cn (Han X); wbhu@tju.edu.cn (Hu W))
} 
TMCs (such as oxides, sulfides, selenides, phosphides, carbides and nitrides) have shown promising prospects in different applications. For example, $\mathrm{MoS}_{2}$ has been proved to be a promising HER electrocatalyst with highly active edge sites [18], $\mathrm{Co}_{3} \mathrm{O}_{4}$ has been widely used for OER in alkaline electrolytes [19], and $\mathrm{ZnMnCoO}_{4}$ has shown comparable ORR activity to commercial Pt/C with high stability in alkaline electrolyte [20]. However, there are still some critical issues that significantly hinder the practical commercialization of TMC-based electrocatalysts [21,22]: 1) the activities of most TMC-based electrocatalysts are still not comparable to precious metalbased catalysts and cannot meet practical applications. For example, industrial electrolyzers require an overpotential of $300 \mathrm{mV}$ to reach a high current density of $500 \mathrm{~mA} \mathrm{~cm}^{-2}$, while it is difficult for most of the reported TMC-based electrocatalysts to meet this requirement. 2) In industrial applications, the electrodes should keep stable at $500 \mathrm{~mA} \mathrm{~cm}^{-2}$ for thousands of hours, while most of the TMC-based electrocatalysts are far from satisfactory due to the structure/composition evolution. Moreover, the intrinsic stability of TMCs would be significantly affected by the aging and polarizing in strong acid/alkaline environment. For example, many TMCbased electrocatalysts show inferior corrosion resistance in the acid electrolytes or under high overpotentials [17]. Due to the surface change during the oxidization/reduction reaction, it is difficult to distinguish the actual active sites of TMCs during the reaction and clarify the reaction mechanisms, which significantly hinder the further improvement of the corresponding electrocatalysts [8]. 3) It has been widely accepted that nano-sized electrocatalysts outperform bulk materials owing to the significantly increased electrochemical surface area (ECSA) and active sites. However, the current industrial preparation of TMCs still employs the gas-solid method, and therefore most of the products are bulks with low electrocatalytic performances. Although the unit prices of bulk TMCs are lower than those of precious metals, their inferior electrocatalytic performances seriously restrict the practical applications. On the other hand, numerous TMC-based electrocatalysts with high activities have been fabricated using hydrothermal, solvothermal and chemical vapor deposition (CVD) methods, while the amplification of large-scale preparation from laboratorial to industrial scale is still a critical problem due to the cost and technological problems.

To meet the current challenges and promote the practical applications of TMC-based electrocatalysts, various design strategies are proposed, including explor- ing new active sites, increasing ECSA to expose more active sites, improving the intrinsic activity of active site and enhancing the electron transfer $[4,23,24]$. As the studies of TMCs for electrocatalysis are being reported rapidly in recent years, there are already many comprehensive reviews about the catalyst design and mechanism. This mini-review aims to summarize the most recently reported advances (since 2018) about TMC-based electrocatalysts for HER, OER, ORR and the relevant devices (such as water splitting devices and Zn-air batteries), and outline the frontiers of this field. At first we briefly introduce the basic characteristics of HER, OER and ORR. Then the selected progresses of transition metal oxides, sulfides, selenides, phosphides, carbides and nitrides for the aforementioned electrocatalytic reactions are comprehensively reviewed. Meanwhile, the new strategies and relevant reaction mechanisms of different electrocatalysts are also summarized (Fig. 1). Finally, the remaining challenges for the further development of TMC-based electrocatalysts are discussed. This review introduces the applicable methods for tuning the physiochemical properties (component, micro/nanostructure and electron distribution) of TMCs, which contributes to developing novel, low-cost and earth-abundant energy electrocatalytic nanomaterials. Moreover, the strategies for optimizing the adsorption/desorption properties, facilitating the charge and mass transfer, and finally enhancing the electrocatalytic performances are also discussed, which

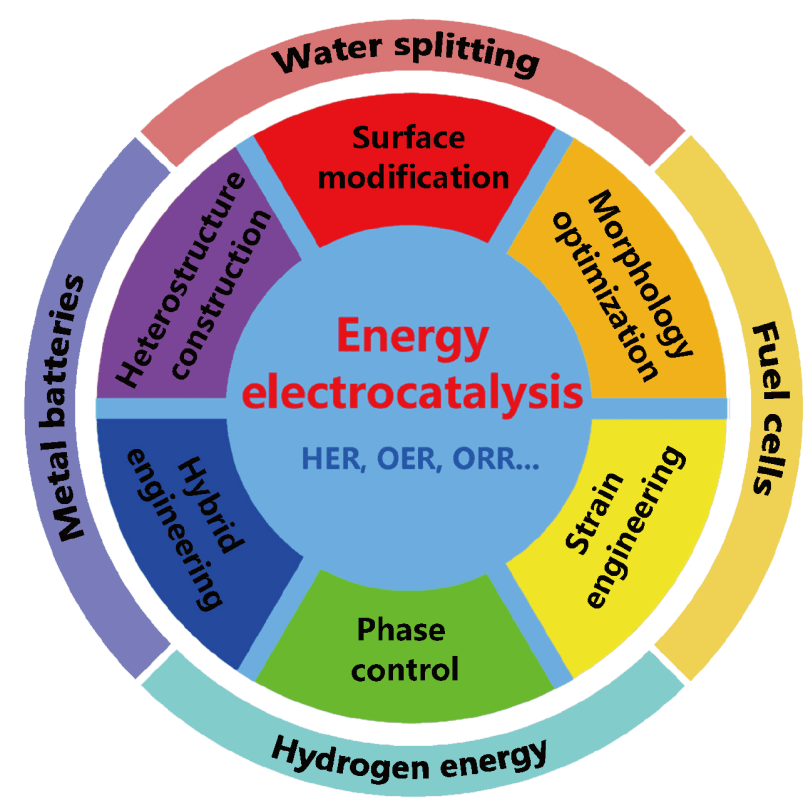

Figure 1 Schematic illustration of the strategies for enhancing the electrocatalytic performance of TMC-based electrocatalysts. 
provides inspirations for further exploring highly efficient electrocatalysts and promoting the practical device applications for energy storage and conversion.

\section{ELECTROCHEMISTRY OF HER, OER AND ORR}

\section{HER}

The multiple elementary steps of HER are as follows [25]:

Volmer step:

$\mathrm{H}^{+}+{ }^{*}+\mathrm{e}^{-} \rightarrow \mathrm{H}^{*}$ (acid),

$\mathrm{H}_{2} \mathrm{O}+{ }^{*}+\mathrm{e}^{-} \rightarrow \mathrm{H}^{*}+\mathrm{OH}^{-}$(alkaline);

Heyrovsky step:

$\mathrm{H}^{*}+\mathrm{e}^{-}+\mathrm{H}^{+} \rightarrow \mathrm{H}_{2}+*$ (acid),

$\mathrm{H}^{*}+\mathrm{e}^{-}+\mathrm{H}_{2} \mathrm{O} \rightarrow \mathrm{H}_{2}+{ }^{*}+\mathrm{OH}^{-}$(alkaline);

Tafel step:

$\mathrm{H}^{*}+\mathrm{H}^{*} \rightarrow \mathrm{H}_{2}+2^{*}$,

where $*$ represents the surface catalytic site. For acid HER, at the first step (Volmer step), a proton is reduced on the active site, which forms an adsorbed $\mathrm{H}$. While for alkaline HER, a $\mathrm{H}_{2} \mathrm{O}$ dissociation step has to proceed to provide a proton before the proton reduction and adsorption, which makes the kinetics more sluggish than acid HER. In the second step, an $\mathrm{H}^{*}$ will react with another proton and electron to form a hydrogen molecule when the surface $\mathrm{H}$ coverage is low (Volmer-Heyrovsky reaction). While two adjoining $\mathrm{H}^{*}$ will directly bind with each other to generate $\mathrm{H}_{2}$ if the $\mathrm{H}$ coverage is high (Volmer-Tafel reaction). Moreover, both the two reaction pathways involve the formation of $\mathrm{H}^{*}$, which plays a critical role in determining the reaction rate. Typically the Gibbs free energy change for $\mathrm{H}^{*}\left(\Delta G_{\mathrm{H}^{*}}\right)$ reflects the intrinsic HER activity and an ideal $\Delta G_{\mathrm{H}^{*}}$ should be close to zero [26].

\section{OER and ORR}

OER involves four elementary steps [27]:

$\mathrm{OH}^{-}+* \rightarrow \mathrm{e}^{-}+\mathrm{OH}^{*}$

$\mathrm{OH}^{*}+\mathrm{OH}^{-} \rightarrow \mathrm{O}^{*}+\mathrm{e}^{-}+\mathrm{H}_{2} \mathrm{O}$

$\mathrm{O}^{*}+\mathrm{OH}^{-} \rightarrow \mathrm{e}^{-}+\mathrm{OOH}^{*}$

$\mathrm{OOH}^{*}+\mathrm{OH}^{-} \rightarrow \mathrm{O}_{2}+*+\mathrm{e}^{-}+\mathrm{H}_{2} \mathrm{O}$.

From the equations above, more electrons and reaction intermediates are involved in OER than HER, which makes OER more kinetically sluggish. As there are three intermediates $\left(\mathrm{OH}^{*}, \mathrm{O}^{*}\right.$ and $\left.\mathrm{OOH}^{*}\right)$ formed during OER and all of the steps are thermodynamically uphill, the step with the highest barrier determines the overall OER rate. Therefore, the binding strength between the intermediates and the active sites significantly affect the reaction kinetics. On the other hand, although the reaction mechanism of acid OER is similar to that of alkaline OER, only $\mathrm{RuO}_{2}$ and $\mathrm{IrO}_{2}$ show satisfactory performances in acid electrolyte, as the strongly oxidizing and acid environment can easily damage most of the TMCs [28]. Therefore, most of the remarkable TMC-based electrocatalysts are applied in alkaline electrolytes.

Similar to OER, most of the ORR electrocatalysts show more efficient performances in alkaline than acid environment. There are two possible ORR reaction pathways in alkaline electrolyte [29]:

(i) Direct $4 \mathrm{e}^{-}$pathway:

$\mathrm{O}_{2}+4 \mathrm{e}^{-}+2 \mathrm{H}_{2} \mathrm{O} \rightarrow 4 \mathrm{OH}^{-}$.

(ii) $2 \mathrm{e}^{-}$to $\mathrm{HO}_{2}^{-}$:

$\mathrm{O}_{2}+\mathrm{H}_{2} \mathrm{O}+2 \mathrm{e}^{-} \rightarrow \mathrm{HO}_{2}^{-}+\mathrm{OH}^{-}$.

Followed by further reduction or decomposition of $\mathrm{HO}_{2}^{-}$:

$\mathrm{HO}_{2}^{-}+\mathrm{H}_{2} \mathrm{O}+2 \mathrm{e}^{-} \rightarrow 3 \mathrm{OH}^{-}$or $2 \mathrm{HO}_{2}^{-} \rightarrow 2 \mathrm{OH}^{-}+\mathrm{O}_{2}$.

Therefore, the $4 \mathrm{e}^{-}$pathway is kinetically faster than $2 \mathrm{e}^{-}$ pathway and most of the TMC-based electrocatalysts with high efficiency follow the $4 \mathrm{e}^{-}$pathway. Similar to OER, the adsorption strength of the intermediates $\left(\mathrm{OH}^{*}, \mathrm{O}^{*}\right.$ and $\mathrm{OOH}^{*}$ ) also critically affects the ORR rate [30].

In summary, although the specific elementary steps of HER, ORR and OER are different, it is clear that the intrinsic reaction activities of HER, OER and ORR are significantly related with the adsorption properties of intermediates on the surface active sites. For example, if HER intermediates bind to the catalytic sites too weakly, the adsorption step (Volmer step) will be hindered and significantly inhibits the following steps. While if the intermediates bind to the surface too strongly, it will be difficult to form products (hydrogen) with smooth desorption from the active sites. Namely, an ideal catalyst should have a suitable binding strength for intermediates in each elementary step: neither too strong nor too weak. By plotting experimental electrochemical activities against the calculated Gibbs free energy $(\Delta G)$ by the density functional theory (DFT), a volcano relationship can be established. Fig. 2 shows some typical volcano plots related with HER, OER and ORR, which clearly show the relationship between the $\Delta G$ and the catalytic activity. Therefore, the free energy is regarded as a useful factor for predicting and explaining the electrocatalytic activities, which has been widely applied in electrocatalytic studies.

\section{ELECTROCATALYSTS FOR HER, OER, ORR AND RELEVANT ENERGY CONVERSION DEVICES}

Various TMC-based electrocatalysts, including oxides, 

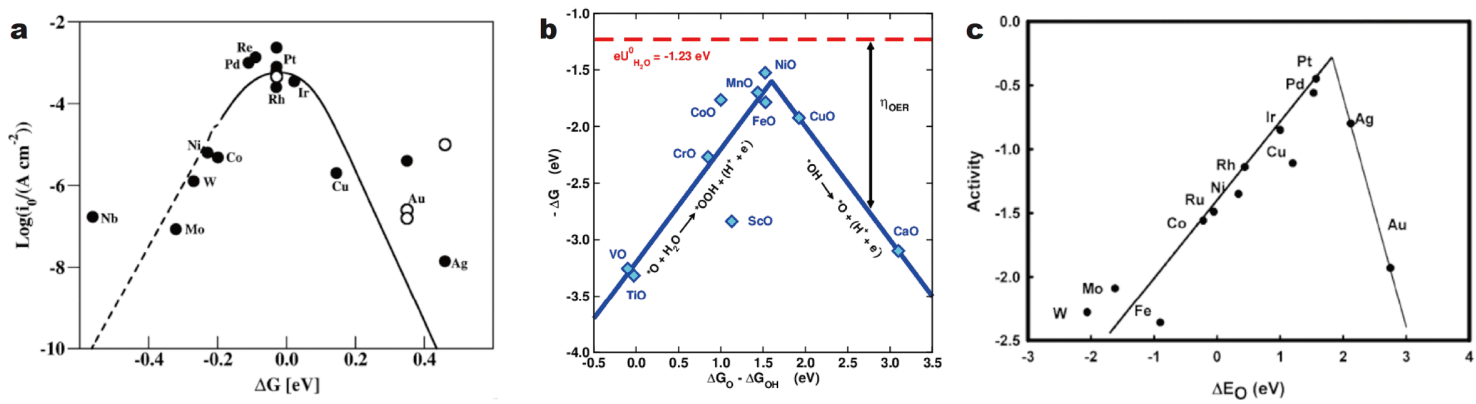

Figure 2 (a) HER, (b) OER, and (c) ORR volcano plots for different electrocatalysts. Reprinted with permission from Ref. [31] (Copyright 2010), [32] (Copyright 2015) and [33] (Copyright 2004), American Chemical Society, respectively.

sulfides, selenides, phosphodes, carbides and nitrides, have been applied in electrocatalytic reactions in recent years. Compared with other compounds (e.g., halogenides, borides and arsenides), these compounds are more promising since the preparation procedures are more facile and safe without using highly toxic non-metallic precursors (e.g., As, $\mathrm{HF}, \mathrm{HCl}$ and $\mathrm{HBr}$ ), and the synthesis methods have been widely developed (such as hydrothermal, solvothermal and annealing methods). Moreover, it is easier to controllably synthesize these TMCbased compounds with tunable phase and composite than other compounds, which would lead to significantly altered physiochemical properties and electrochemical performances. Up to date, many earth-abundant and lowcost catalysts have shown excellent electrocatalytic performances which are comparable to noble metals, while the property of each kind of compound is different and the corresponding fabrication strategy and reaction mechanism are also different. This part will summarize recent and representative advances of TMCs classified by non-metallic elements and the optimization strategies are also discussed.

\section{Transition metal oxides}

Transition metal oxide-based electrocatalysts have been widely developed owing to their low toxicity, low cost and abundant reserves [34]. Moreover, owing to the surface oxygen-containing groups and the different cationic oxidation states of transition metals, the adsorption and activation of oxygen molecules on the oxide surface are naturally suitable [35]. However, their poor electron transfer ability and limited intrinsic activity are still needed to be further improved. Many efforts are made to improve their hydrogen and oxygen electrocatalytic activities via various design strategies [36-40]. Exposing facets with higher electrocatalytic activity has been proved to be an effective way for improving the performance.
Han et al. [41] prepared crystallized $\mathrm{Co}_{3} \mathrm{O}_{4}$ nanomaterials with exposed planes $(\{001\},\{001\}+\{111\}$, and $\{112\})$ via a facile and template-free hydrothermal strategy. In $\{001\}$ and $\{111\}$ planes, Co ions occupy the tetrahedral coordination $\left(\mathrm{Co}^{2+} \mathrm{Td}\right)$ (Fig. 3a). While in $\{112\}$ plane, Co ions occupy not only tetrahedral coordination but also octahedral coordination $\left(\mathrm{Co}^{3+} \mathrm{Oh}\right)$. According to the ligand field theory, $\mathrm{Co}^{3+} \mathrm{Oh}$ has a stronger electron donating ability and therefore is beneficial for the reduction of $-\mathrm{OH}$ and $\mathrm{O}_{2}{ }^{2-}$. Furthermore, DFT calculations reveal that $\{112\}$ surface has a moderate oxygen binding ability compared with $\{001\}$ and $\{111\}$ planes. As a result, the $\{112\}$ faceted $\mathrm{Co}_{3} \mathrm{O}_{4}$ electrocatalyst showed high ORR performance with a diffusion-limited current density of $5.48 \mathrm{~mA} \mathrm{~cm}^{-2}$ and a smaller Tafel slope $\left(62 \mathrm{mV} \mathrm{dec}^{-1}\right)$ than that of $\mathrm{Pt} / \mathrm{C}\left(69 \mathrm{mV} \mathrm{dec}^{-1}\right)$ (Fig. 3b). Anion/cation doping has been widely applied for tuning the intrinsic activity of catalytic sites [42]. Peng et al. [43] prepared highly porous S-doped $\mathrm{CaMnO}_{3}(\mathrm{CMO})$ nanotubes via combining electrospinning, heat calcination, and sulfurization treatment, in which sulfur was doped onto the surface of $\mathrm{CaMnO}_{3}$ nanotubes to engineer the electronic and defective properties of the pristine material. After the introduction of sulfur, the intrinsic conductivity and oxygen vacancies were significantly increased, which helped to enhance the electron transfer and increase the exposure of catalytic sites during the reaction. Moreover, the DFT calculations revealed that the adsorption properties of the reaction intermediates were significantly optimized by the sulfur dopants. As a result, the as-prepared $\mathrm{CMO} / \mathrm{S}$ nanomaterials showed significantly enhanced OER $\left(E_{j=10 \mathrm{~mA} \mathrm{~cm}}{ }^{-2}=1.7 \mathrm{~V} v s\right.$. RHE) and ORR ( $E_{\text {half }}$ $=-0.760 \mathrm{~V} v$ s. RHE) performances in alkaline electrolyte. Moreover, the $\mathrm{CMO} / \mathrm{S}$-based rechargeable $\mathrm{Zn}$-air battery exhibited an outstanding performance. Li et al. [44] investigated the effect of $\mathrm{N}$ dopants on the OER activity of $\mathrm{N}$-doped $\mathrm{Co}_{3} \mathrm{O}_{4}$ nanostructures $\left(\mathrm{N}-\mathrm{Co}_{3} \mathrm{O}_{4}\right)$, which was 

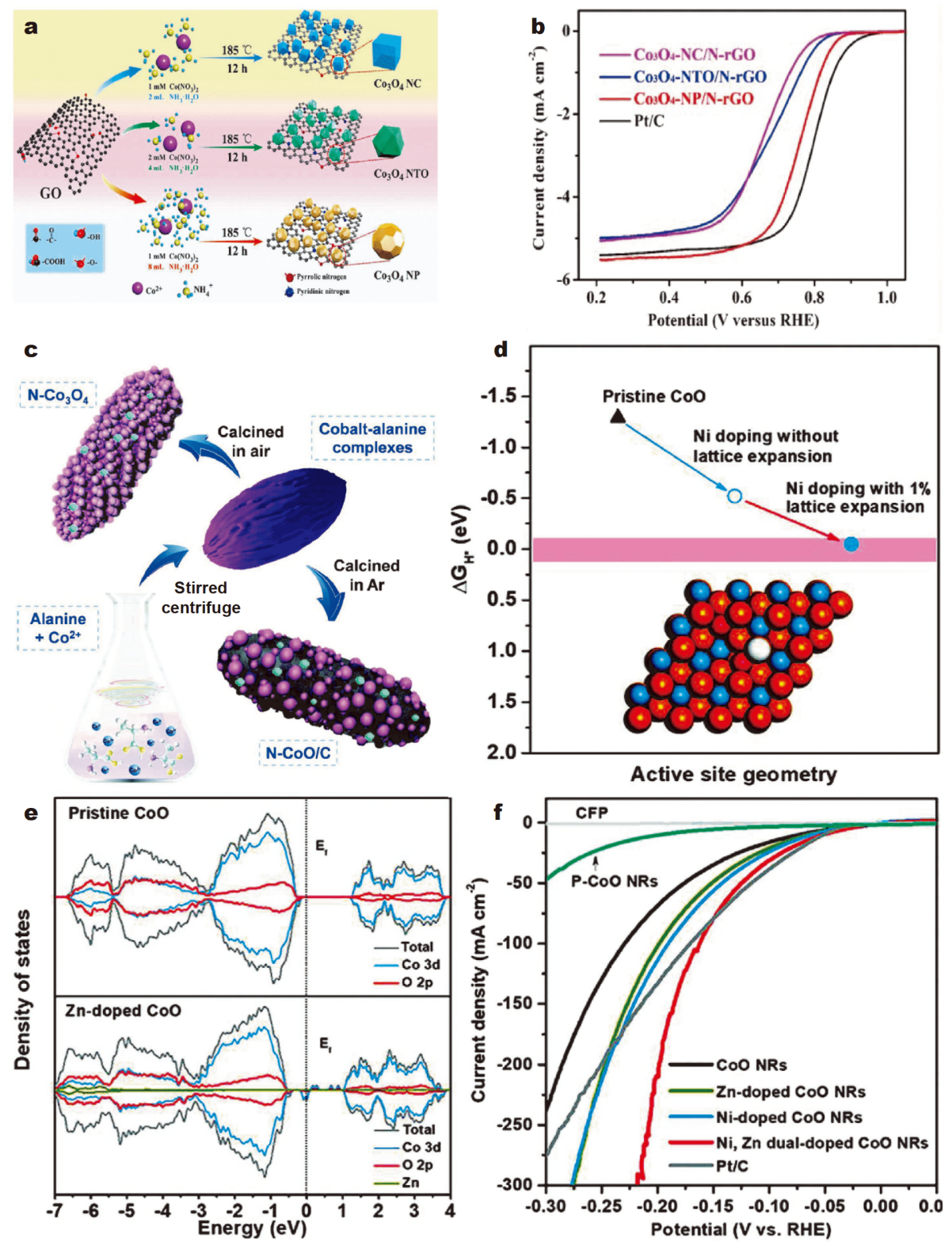

Figure 3 (a) Schematic illustration for preparation of different $\mathrm{Co}_{3} \mathrm{O}_{4}$ electrocatalysts, (b) linear sweep voltammetry (LSV) of different samples at $1600 \mathrm{rpm}$ in $\mathrm{O}_{2}$-saturated $0.1 \mathrm{~mol} \mathrm{~L}^{-1} \mathrm{KOH}$ solution. Reprinted with permission [41]. Copyright 2018, Wiley. (c) A simple synthesis scheme of the asprepared samples. Reprinted with permission [44]. Copyright 2018, Wiley. (d) DFT calculated hydrogen adsorption free energy, $\Delta G_{\mathrm{H}^{*}}$, on pristine $\mathrm{CoO}$, Ni-doped $\mathrm{CoO}$ (with $\sim 11 \%$ surface Ni dopant concentration), and the strained Ni-doped CoO (with $1 \%$ tensile strain), (e) Density of states of pristine $\mathrm{CoO}$ and $\mathrm{Zn}$-doped $\mathrm{CoO}$ (with $\sim 2 \% \mathrm{Zn}$ dopant concentration), (f) LSVs of different catalysts recorded in 1 mol L $\mathrm{L}^{-1} \mathrm{KOH}$. Reprinted with permission [45]. Copyright 2019, Wiley.

prepared via the pyrolysis of cobalt-alanine complexes in air (Fig. 3c). DFT calculations demonstrated that the $\mathrm{O}-\mathrm{H}$ bond of the intermediate $\mathrm{OH}^{-}$on $\mathrm{N}-\mathrm{Co}_{3} \mathrm{O}_{4}$ was $0.99 \AA$ and longer than that on $\mathrm{Co}_{3} \mathrm{O}_{4}(0.98 \AA)$, indicating stronger adsorption of $\mathrm{OH}^{-}$and the OER kinetics was therefore boosted. Moreover, the bandgap was significantly narrowed from 1.80 to $1.42 \mathrm{eV}$ on $\mathrm{N}-\mathrm{Co}_{3} \mathrm{O}_{4}$, and the charge transfer was facilitated during the reaction. Ling et al. [45] developed $\mathrm{Ni}, \mathrm{Zn}$ co-doped $\mathrm{CoO}$ nanorods as HER electrocatalysts using a cation exchange strategy and different cations were found to play different roles in enhancing the HER performance. Due to the DFT calculations, compared with unmodified $\mathrm{CoO}$, more electrons migrated to the surface $\mathrm{O}$ in $\mathrm{Ni}-\mathrm{CoO}$ from the 
neighboring $\mathrm{Ni}$, which helped to weaken the binding strength between adsorbed hydrogen and active sites. Therefore, the $\Delta G_{\mathrm{H}^{*}}$ was significantly reduced to an ideal value $(-0.05 \mathrm{eV})$ (Fig. $3 \mathrm{~d})$. On the other hand, the projected density of state (PDOS) results revealed a significantly increased conductivity and carrier concentration in $\mathrm{Zn}-\mathrm{CoP}$ (Fig. 3e), which facilitated the electron transfer from the electrode to the surface catalytic sites. The HER activity of the as-prepared $\mathrm{Ni}, \mathrm{Zn}$ $\mathrm{CoO}$ nanorods was superior to many reported metal oxides with an overpotential of $79 \mathrm{mV}$ at $20 \mathrm{~mA} \mathrm{~cm}^{-2}$ (Fig. 3f). Zhao et al. [46] prepared $\mathrm{Co}-\mathrm{MnO}_{2} \mid \mathrm{OV}$ ultrathin nanosheets (NSs) through a spontaneous redox reaction between $\mathrm{Co} / \mathrm{NCNFs}$ and $\mathrm{KMnO}_{4}$. Compared with the unmodified $\mathrm{MnO}_{2}$, the Co dopants led to the formation of $\mathrm{Co}-\mathrm{MnO}_{2} \mid \mathrm{OV}$ ultrathin NSs and a large amount of oxygen vacancies were in-situ formed during the preparation process. Owing to the advantageous structural properties, faster charge transfer and higher exposure of catalytic sites were achieved. On the other hand, the DFT calculations demonstrated that the electrons were more delocalized on $\mathrm{Co}-\mathrm{MnO}_{2} \mid \mathrm{OV}$, which led to a higher electronegativity and increased charge transfer ability. Meanwhile, the calculation of free energy change revealed that the energy barrier of the rate-determining step was reduced after the introduction of Co dopant and oxygen vacancies on $\mathrm{MnO}_{2}$. Finally, the Co- $\mathrm{MnO}_{2} \mid \mathrm{OV}$ showed a good OER with $10 \mathrm{~mA} \mathrm{~cm}^{-2}$ at $279 \mathrm{mV}$. Liu et al. [47] prepared an ultrathin amorphous cobaltvanadium hydr(oxy)oxide (CoV-UAH) by dropping an alkaline solution with ammonium metavanadate into an aqueous cobaltous solution. The in-situ X-ray absorption near edge structure (XANES) spectra demonstrated that the introduction of $\mathrm{V}$ significantly promoted the formation of the real OER catalytic sites (CoOOH). Meanwhile, the electrochemical impedance spectroscopy (EIS) data demonstrated an enhanced charger transfer ability on CoV-UAH, which was owing to the ultrathin nanostructure and abundant catalytic sites. Moreover, the DFT calculations revealed that the energy barrier of elementary step on Co site was optimized by the neighboring $\mathrm{V}$ atom, thus the intrinsic activity was also enhanced. As a result, the CoV-UAH required only $250 \mathrm{mV}$ to reach $10 \mathrm{~mA} \mathrm{~cm}^{-2}$, which was a remarkable OER activity in alkaline electrolyte.

Constructing hybrid nanomaterials with heterostructures is another strategy for enhancing the electrocatalytic performance $[48,49]$. Yan et al. [50] engineered a nanocrystalline $\mathrm{CeO}_{2}$ /amorphous $\mathrm{Ni}(\mathrm{OH})_{2}$ hybrid $\left(\mathrm{NiCeO}_{x} \mathrm{H}_{y}\right)$ for alkaline via an electrochemical deposition method (Fig. 4a). As a result, the $\mathrm{NiCeO}_{x} \mathrm{H}_{\mathrm{y}}$ electrode outperformed the commercial $\mathrm{RuO}_{2}$ with an overpotential of $177 \mathrm{mV}$ at $10 \mathrm{~mA} \mathrm{~cm}$ and a high stability over $300 \mathrm{~h}$ at $1000 \mathrm{~mA} \mathrm{~cm}^{-2}$ (Fig. 4b). It was found that
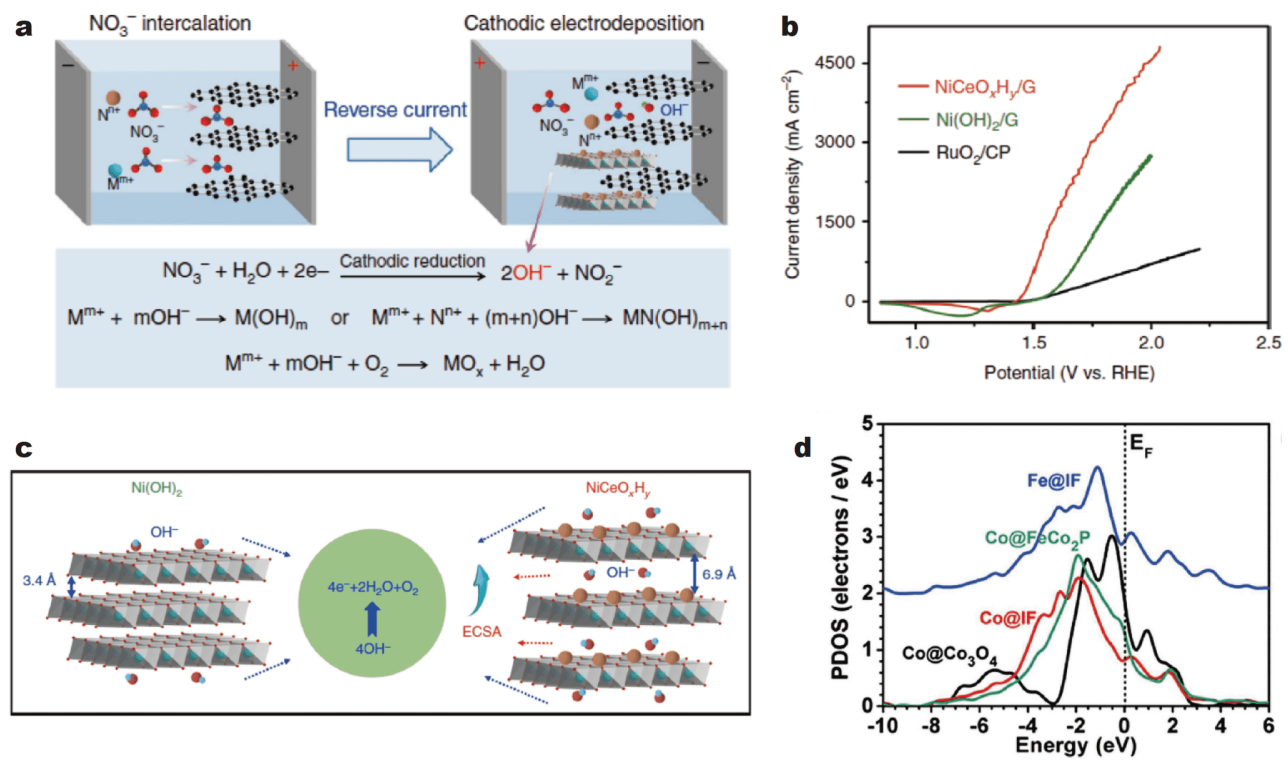

Figure 4 (a) The schematic two-step synthesis and the reaction mechanisms of the cathodic electrodeposition of metal hydroxides $\left(\mathrm{M}(\mathrm{OH})_{m}\right.$ or $\left.\mathrm{MN}(\mathrm{OH})_{m+n}\right)$, and oxides $\left(\mathrm{MO}_{x}\right) \cdot \mathrm{M}^{m+}$ and $\mathrm{N}^{n+}$ are metal cations; (b) polarization curves (scan rate $10 \mathrm{mV} \mathrm{s}^{-1}$ ) of different electrodes; (c) illustration showing that the OER was favored on $\mathrm{NiCeO}_{x} \mathrm{H}_{y}$ with larger interlamellar spacing and higher ECSA compared with $\mathrm{Ni}(\mathrm{OH})_{2}$, respectively. Reprinted with permission [50]. Copyright 2018, Nature Publishing Group. (d) The PDOSs of the Co-3d-bands from different regions within the IF system. Reprinted with permission [51]. Copyright 2018, Wiley. 
the $\mathrm{CeO}_{2}$ in $\mathrm{NiCeO}_{x} \mathrm{H}_{y}$ promoted the formation of $\gamma$ $\mathrm{NiOOH}$ with larger layer lattices than unmodified $\mathrm{Ni}(\mathrm{OH})_{2}$, which significantly increased the electrochemically active surface area (ECSA), exposed more catalytic sites for OER and enhanced the migration of reactants (Fig. 4c). Moreover, the electronic properties of $\mathrm{Ni}$ were modified by $\mathrm{Ce}$, and the DFT calculations revealed that the adsorption properties of the intermediates were also optimized. Zhang et al. [51] constructed a $\mathrm{Co}_{3} \mathrm{O}_{4} / \mathrm{Fe}_{0.33} \mathrm{Co}_{0.66} \mathrm{P}$ interface by partially etching $\mathrm{Co}\left(\mathrm{CO}_{3}\right)_{0.5}(\mathrm{OH}) \cdot 0.11 \mathrm{H}_{2} \mathrm{O}-\mathrm{Co}-\mathrm{CHH}$ nanowire with $\mathrm{Fe}(\mathrm{CN})_{6}{ }^{3-}$ to form the precursor $\mathrm{Co}-\mathrm{CHH} / \mathrm{FeCO}_{2}(\mathrm{CN})_{6}$, followed by phosphorization with $\mathrm{NaH}_{2} \mathrm{PO}_{2} \cdot \mathrm{H}_{2} \mathrm{O}$ under $350^{\circ} \mathrm{C}$. The PDOS results demonstrated that the d-band of Co site on the interface was downshifted (Fig. 4d), which helped to weaken the overbinding effect and facilitate the adsorption/desorption of oxygen species during OER. Moreover, the overlapping effects of $\mathrm{O} 2 \mathrm{p}$ and $\mathrm{H}$ 1s orbitals of the intermediates were also optimized. Consequently, the OER energy barrier of each elementary step on $\mathrm{Co}_{3} \mathrm{O}_{4} / \mathrm{Fe}_{0.33} \mathrm{Co}_{0.66} \mathrm{P}$ was significantly lowered and the electron current density was increased. Experimental results proved the DFT results and the $\mathrm{Co}_{3} \mathrm{O}_{4} /$ $\mathrm{Fe}_{0.33} \mathrm{Co}_{0.66} \mathrm{P}$ exhibited a low overpotential of $215 \mathrm{mV}$ at $50 \mathrm{~mA} \mathrm{~cm}^{-2}$. Yu et al. [52] fabricated a series of Ni-Mo-O catalysts for HER and urea oxidation reaction (UOR) via annealing $\mathrm{NiMoO}_{4} \cdot x \mathrm{H}_{2} \mathrm{O}$ in $\mathrm{H}_{2}$ and $\mathrm{Ar}$, respectively. The
$\mathrm{H}_{2}$-reduced sample led to the formation of $\mathrm{Ni} / \mathrm{NiO} / \mathrm{MoO}_{x}$ composite with a synergistic effect: water molecule was firstly dissociated on $\mathrm{NiO}$ into hydrogen, which was then stabilized on $\mathrm{Ni}$ and finally formed $\mathrm{H}_{2}$ on $\mathrm{MoO}_{x}$. On the other hand, the Ar-calcined sample formed $\mathrm{NiMoO}_{4}$ composite, where $\mathrm{Mo}^{6+}$ made it easier for $\mathrm{Ni}^{2+}$ to be oxidized to $\mathrm{Ni}^{3+}$ and promoted the UOR activity. Consequently, the urea electrolyzer composed of $\mathrm{Ni} / \mathrm{NiO} /$ $\mathrm{MoO}_{x}$ (cathode) and $\mathrm{NiMoO}_{4}$ (anode) exhibited a remarkable low cell voltage of $1.38 \mathrm{~V}$ at $10 \mathrm{~mA} \mathrm{~cm}^{-2}$.

There are also some other studies that combine different strategies to design the composite and structure of catalysts. For example, An et al. [53] simultaneously investigated the effect of anion dopant and the interface on HER and OER. A heterogeneous electrocatalyst (N$\mathrm{NiMoO}_{4} / \mathrm{NiS}_{2}$ ) was engineered via $\mathrm{N}$ doping and sulfuration of $\mathrm{NiMoO}_{4}$ nanowires. The PDOS results revealed that the $\mathrm{N}$ dopants led to a higher occupation at Fermi level in $\mathrm{N}-\mathrm{NiMoO}_{4}$ compared with $\mathrm{NiMoO}_{4}$ (Fig. 5a), which strengthened the adsorption of reaction intermediates. Moreover, the bandgap was also decreased and the charge transfer was therefore facilitated. On the other hand, the electrons were proved to migrate from $\mathrm{NiMoO}_{4}$ to $\mathrm{NiS}_{2}$ through the heterojunction (Fig. 5b), which contributed to stabilizing the adsorbed $\mathrm{H}$ atom and facilitating the HER kinetics. Besides, the reduced electron concentration of $\mathrm{NiMoO}_{4}$ led to a higher valence
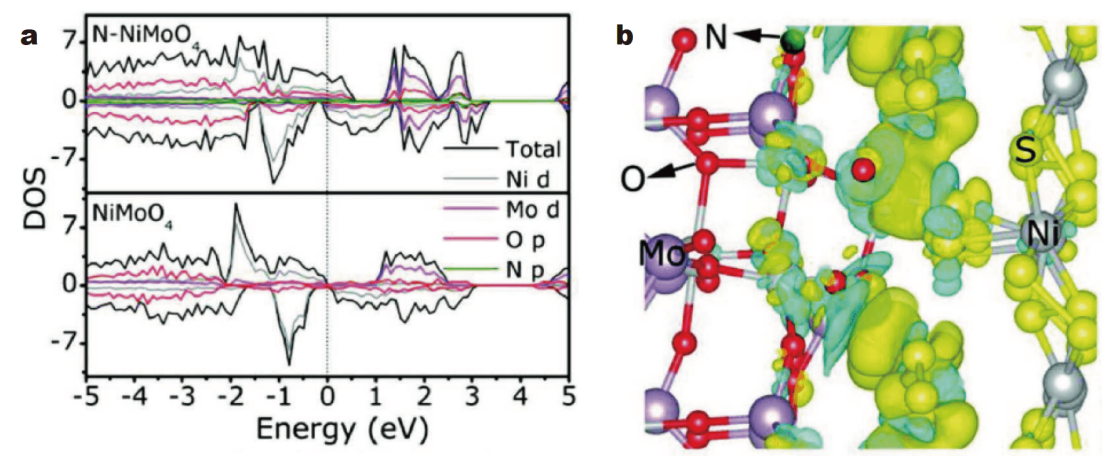

c

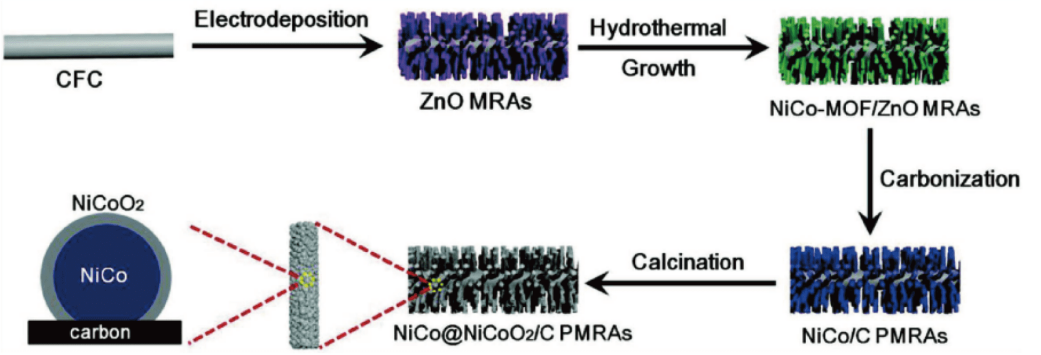

Figure 5 (a) PDOS of different samples; (b) differential charge density of $\mathrm{N}-\mathrm{NiMoO}_{4} / \mathrm{NiS}_{2}$ heterojunction. Reprinted with permission [53]. Copyright 2019, Wiley. (c) Process of preparing NiCo@NiCoO$/ 2$ PMRAs. Reprinted with permission [54]. Copyright 2018, Wiley. 
state of $\mathrm{Ni}$ and helped to enhance the OER activity. Finally, the electrolyzer assembled by $\mathrm{N}-\mathrm{NiMoO}_{4} / \mathrm{NiS}_{2}$ as both anode and cathode required only $1.6 \mathrm{~V}$ to reach $10 \mathrm{~mA} \mathrm{~cm}^{-2}$. Xu et al. [54] fabricated porous microrod arrays composed of carbon-confined $\mathrm{NiCo@NiCoO}$ core@shell nanoparticles ( $\mathrm{NiCo} @ \mathrm{NiCoO}_{2} / \mathrm{C} \quad \mathrm{PMRAs}$ ) through carbonization and calcination of $\mathrm{NiCo}-\mathrm{MOF} /$ $\mathrm{ZnO}$ microrod arrays (Fig. 5c). The microstructures exhibited a high ECSA with abundant catalytic sites for OER, and the charge transfer was facilitated by the surface oxygen vacancies of $\mathrm{NiCoO}_{2}$. Consequently, the electrode of $\mathrm{NiCo@NiCoO} / \mathrm{C}$ PMRAs required an overpotential of only $366 \mathrm{mV}$ to reach $20 \mathrm{~mA} \mathrm{~cm}^{-2}$ and exhibited a high stability of $20 \mathrm{~h}$. Duan et al. [55] fabricated a series of $\mathrm{ZnCo}_{2-x} \mathrm{Ni}_{x} \mathrm{O}_{4}(x=0-2)$ catalysts via thermal decomposition of a mixture of $\mathrm{Zn}(\mathrm{OAc})_{2} \cdot 2 \mathrm{H}_{2} \mathrm{O}$ and $\mathrm{Co}\left(\mathrm{NO}_{3}\right)_{2} \cdot 6 \mathrm{H}_{2} \mathrm{O}$ with turnable $\mathrm{Zn} / \mathrm{Co}$ ratios. Via DFT $+U$ calculations, they first found the gap between the $\mathrm{O}$ pband and $\mathrm{M}_{\mathrm{oh}}$ (Co and $\mathrm{Ni}$ ) d-band center in the nanomaterial significantly affected the stability. Namely, when $x \leq 0.4$, the energy of $\mathrm{O}$ was close to or lower than that of $\mathrm{M}_{\mathrm{oh}}$, indicating that the lattice was stable and it was hard to release lattice oxygen. However, when $x \geq 0.6$, the energy of $\mathrm{O}$ rapidly increased and therefore the metastable structure with unstable lattice oxygen formed. On the other hand, the lowest unoccupied molecular orbital (LUMO) of the lattice reflected the ability to release lattice oxygen in the spinel and therefore was correlated with the OER activity. The LUMO changed from Nisubstitution demonstrated that $33 \% \mathrm{Ni}$-substitution led to the lowest LUMO of the spinel. Therefore the $\mathrm{ZnCo}_{1.4}$ $\mathrm{Ni}_{0.6} \mathrm{O}_{4}$ and $\mathrm{ZnCo}_{1.2} \mathrm{Ni}_{0.8} \mathrm{O}_{4}$ would exhibit more active redox and release more lattice oxygen during the reaction. The electrochemical test matched well with the theoretical results. Surface reconstruction was easily induced on both $\mathrm{ZnCo}_{1.4} \mathrm{Ni}_{0.6} \mathrm{O}_{4}$, and $\mathrm{ZnCo}_{1.2} \mathrm{Ni}_{0.8} \mathrm{O}_{4}$, and the active phase $(\mathrm{NiOOH})$ was formed after a few cycles. Consequently, the metastable spinel catalysts significantly outperformed other stable spinels. Table 1 summarizes the performances of some representative oxide-based electrocatalysts.

\section{Transition metal sulfides}

Transition metal sulfides have shown unique physicochemical properties and a significantly enhanced conductivity compared with metal oxides, which make them promising candidates for many electrochemical applications [56-63]. Due to the higher electronegativity, the S sites in the sulfides can withdraw electrons from the metals and then act as efficient active sites for reactant adsorption and activation [64]. Meanwhile, in alkaline HER, the $\mathrm{S}$ sites can promote the water dissociation via forming the $\mathrm{S}^{\sigma+}-\mathrm{TM}^{n+}-\mathrm{H}_{2} \mathrm{O}$ network. Different strategies have also been developed for the improvement of transition metal sulfides. Exploring highly active facets for electrocatalysis is important for improving the activity. Dong et al. [65] prepared a highly porous $\mathrm{Ni}_{3} \mathrm{~S}_{2}$ thin film $\left(\mathrm{Ni}_{3} \mathrm{~S}_{2} \mathrm{NTFs}\right)$ via sulfidation of anodized nickel oxide supported on nickel foils. They successfully prepared $\mathrm{Ni}_{3} \mathrm{~S}_{2}$ NTFs and dominatingly exposed (003) facet consisted of $\mathrm{Ni}_{3}$-triangle and $\mathrm{S}$ atoms. Theoretical calculations demonstrated that the $\mathrm{Ni}_{3} \mathrm{~S}_{2}$ was metallic with high electron conductivity. Meanwhile, the porous structure exposed abundant catalytic sites and enhanced the mass transfer, and the surface exhibited a hydrophilic property that enabled good adsorption of reactants. Moreover, both the water dissociation and the hydrogen adsorption/ desorption ability were significantly enhanced on $\mathrm{Ni}_{3} \mathrm{~S}_{2}$

Table 1 Comparison of the performances of transition metal oxide-based electrocatalysts for different applications

\begin{tabular}{|c|c|c|c|c|c|}
\hline Catalyst & Substrate & $\begin{array}{l}\text { Electrolyte } \\
\text { /reaction }\end{array}$ & $\begin{array}{l}\text { Overpotential } \\
(\mathrm{mV}) @ \mathrm{~mA} \mathrm{~cm}{ }^{-2}\end{array}$ & $\begin{array}{c}\text { Tafel slope } \\
\left(\mathrm{mV} \text { decade }^{-1}\right)\end{array}$ & $\begin{array}{c}\text { Stability } \\
\left(\mathrm{mA} \mathrm{cm}^{-2} @ \mathrm{~h}\right)\end{array}$ \\
\hline $\mathrm{Co}_{3} \mathrm{O}_{4}-\mathrm{NP} / \mathrm{N}-\mathrm{rGo}[41]$ & Carbon cloth & $1 \mathrm{~mol} \mathrm{~L}^{-1} \mathrm{KOH} / \mathrm{OER}$ & $380 @ 10$ & 62 & \\
\hline $\mathrm{CaMnO}_{3} / \mathrm{S}[43]$ & Carbon paper & $0.1 \mathrm{~mol} \mathrm{~L}^{-1} \mathrm{KOH} / \mathrm{OER}$ & 470@10 & 52 & 2000 cycles \\
\hline $\mathrm{N}-\mathrm{Co}_{3} \mathrm{O}_{4}[44]$ & Ni foam & $0.1 \mathrm{~mol} \mathrm{~L}^{-1} \mathrm{KOH} / \mathrm{OER}$ & 300@10 & 36.3 & 10@1 \\
\hline $\mathrm{Ni}, \mathrm{Zn}$ dual-doped $\mathrm{CoO}[45]$ & Carbon fiber paper & $1 \mathrm{~mol} \mathrm{~L}^{-1} \mathrm{KOH} / \mathrm{HER}$ & 53@10 & & 10@24 \\
\hline $\mathrm{Co}-\mathrm{MnO}_{2}[46]$ & Glassy carbon & $1 \mathrm{~mol} \mathrm{~L}^{-1} \mathrm{KOH} / \mathrm{OER}$ & 279@10 & 75 & $10 @ 12$ \\
\hline CoV-UAH [47] & Glassy carbon & $1 \mathrm{~mol} \mathrm{~L}^{-1} \mathrm{KOH} / \mathrm{OER}$ & 250@10 & 44 & $40 @ 170$ \\
\hline $\mathrm{NiCeO}_{x} \mathrm{H}_{y}[50]$ & Glassy carbon & $1 \mathrm{~mol} \mathrm{~L}^{-1} \mathrm{KOH} / \mathrm{OER}$ & 177@10 & 22 & 1000@300 \\
\hline $\mathrm{Co}_{3} \mathrm{O}_{4} / \mathrm{Fe}_{0.33} \mathrm{Co}_{0.66} \mathrm{P}[51]$ & Ni foam & $1 \mathrm{~mol} \mathrm{~L}^{-1} \mathrm{KOH} / \mathrm{OER}$ & 215@50 & 59.8 & 240@150 \\
\hline $\mathrm{N}-\mathrm{NiMoO}_{4} / \mathrm{NiS}_{2}[53]$ & $\mathrm{CFC}$ & $1 \mathrm{~mol} \mathrm{~L}^{-1} \mathrm{KOH} / \mathrm{OER}$ & 283@10 & 44.3 & 20@29 \\
\hline $\mathrm{NiCo@NiCoO} / \mathrm{C}[54]$ & $\mathrm{CFC}$ & $1 \mathrm{~mol} \mathrm{~L}^{-1} \mathrm{KOH} / \mathrm{OER}$ & 366@20 & 83.97 & $20 @ 20$ \\
\hline
\end{tabular}


(003) facet with $\mathrm{Ni}_{3}$-triangle and $\mathrm{S}$ atoms (Fig. 6a, b). The electrolyzer using $\mathrm{Ni}_{3} \mathrm{~S}_{2}$ NTFs as electrodes required only $1.611 \mathrm{~V}$ to reach $10 \mathrm{~mA} \mathrm{~cm}^{-2}$.

Tuning the ratio of anion/cation in the material can also induce a varied intrinsic activity. Li et al. [66] prepared $\mathrm{a}-\mathrm{MoS}_{x}(x=2.73)$ via a controllable laser ablation method from the aqueous phase Mo precursor (Fig. 6c). The as-synthesized a-MoS ${ }_{x}$ maximized the ratio of $\mathrm{Mo}^{\mathrm{V}}$ defects compared with $\mathrm{MoS}_{2}$ or $\mathrm{MoS}_{3}$, and the number of bridging ligands of $\mathrm{S}_{2}{ }^{2-}$ was also optimized. Theoretical and experimental results demonstrated that the $\mathrm{Mo}^{\mathrm{V}}$ defects and bridging $\mathrm{S}_{2}{ }^{2-}$ were excellent HER sites. Meanwhile, the charge resistance was reduced and more active sites were exposed on $\mathrm{MoS}_{x}$. Therefore, the HER performance of $\mathrm{MoS}_{x}$ was superior to those of other molybdenum sulfides. Yang et al. [67] synthesized CoNiFe sulfide nanospheres with numerous mesopores (CoNiFe-S MNs) (Fig. 6d) as a durable electrocatalyst for OER and ORR through a simple two-step solvothermal method. The trimetallic ions in the composite had a cooperative effect on the mesoporous structure and the outstanding catalytic performance. Among trimetallic ions, the incorporation of Fe was employed as an electron donor that provided electrons to $\mathrm{Co}$ and $\mathrm{Ni}$ to weaken the oxygen adsorption and favor the reaction. In addition, both the mesopores and the synergistic effect of trimetallic ions enlarged the electrochemical double-layer capacitance and exposed more catalytic sites for OER. As a result, the CoNiFe-S MNs exhibited outstanding OER (an overpotential of $199 \mathrm{mV}$ at $10 \mathrm{~mA} \mathrm{~cm}^{-2}$ ) and ORR performances (a half wave potential of $0.78 \mathrm{~V}$ ) with high stability. Kong et al. [68] prepared a three-dimensional (3D) hybrid Ni-Mo sulfide material supported by carbon textiles $\left(\mathrm{NiMo}_{3} \mathrm{~S}_{4} / \mathrm{CTs}\right)$ using a facile hydrothermal method followed by post-annealing. Owing to the insertion of $\mathrm{Ni}$ into the $\mathrm{MoS}_{2}$ lattice, the interlayer spacing was enlarged and therefore more catalytic sites with abundant defects were formed. Meanwhile, the 3D nanostructure increased the ECSA and facilitated the electron and ion transfer. Besides, the carbon textile also helped to reduce the charge resistance and inhibited the agglomeration of sulfides during the reaction. The $\mathrm{NiMo}_{3} \mathrm{~S}_{4} / \mathrm{CT}$ s showed an efficient HER performance with a high stability.

Engineering heterostructures can also improve the electrocatalytic performance of metal sulfides [69]. $\mathrm{Mu}$ thurasu et al. [70] engineered a $\mathrm{Co}_{3} \mathrm{O}_{4} / \mathrm{MoS}_{2}$ heterostructure via immersing $\mathrm{Co}_{3} \mathrm{O}_{4}$ in $\mathrm{MoS}_{2}$-containing dimethyl formamide (DMF) solution followed by a solvothermal process under $200^{\circ} \mathrm{C}$, causing a strong interaction between the two compounds. The $\mathrm{MoS}_{2}$ enhanced the exposure of cobalt sites that acted as the OER active centers. Meanwhile, $\mathrm{MoS}_{2}$ promoted the adsorption of OER intermediates and therefore facilitated the reaction kinetics. In return, the electron transfer between $\mathrm{S}$ and $\mathrm{O}$
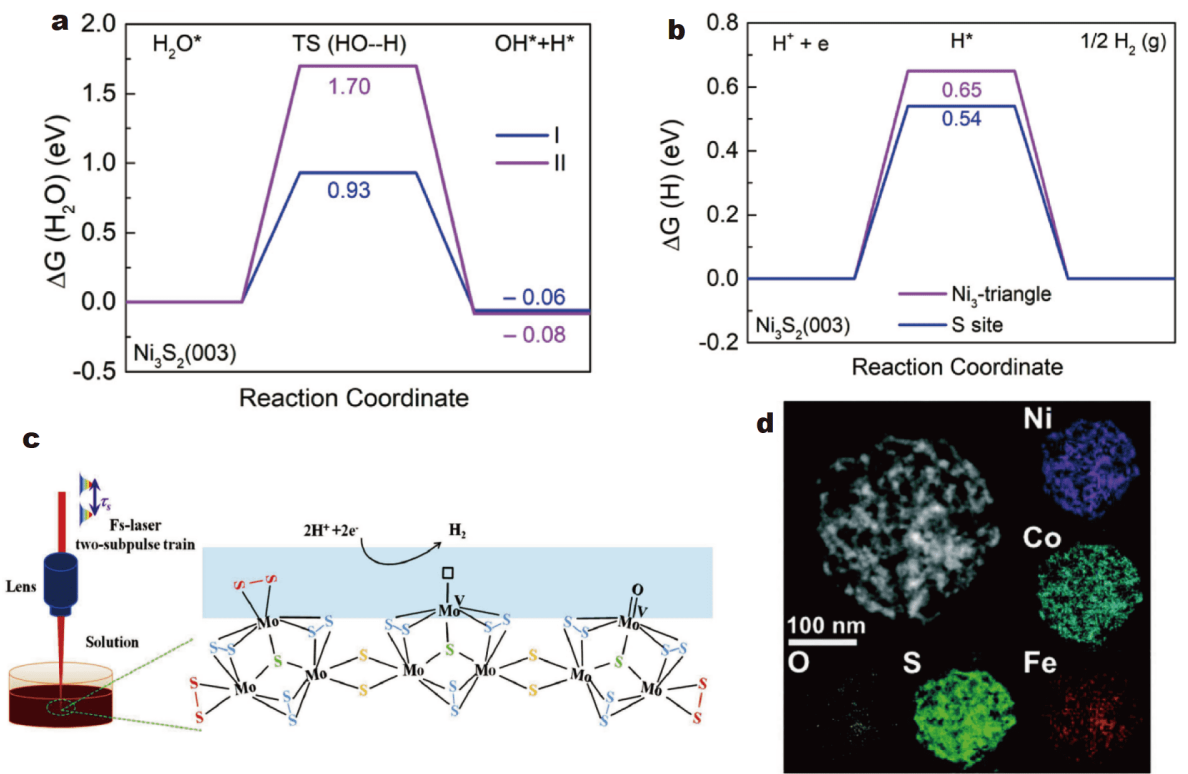

Figure 6 Calculated adsorption free energy diagrams for the (a) Volmer step and (b) Tafel step on the $\mathrm{Ni}_{3} \mathrm{~S}_{2}(003)$ facet model. Reprinted with permission [65]. Copyrith 2019, Elsevier. (c) Schematic of the preparation process, structure of a-MoS ${ }_{x}$, and HER catalytic mechanism. Reprinted with permission [66]. Copyright 2019, Wiley. (d) High angle annular dark field scanning transmission electron microscope (HAADF-STEM) and elemental mapping images of $\mathrm{NiCo}_{2} \mathrm{~S}_{4}$ and $\mathrm{FeNi}_{2} \mathrm{~S}_{4}$. Reprinted with permission [67]. Copyright 2018, Wiley. 
on the interface promoted the conductivity and induced higher adsorption of proton during HER. Consequently, $\mathrm{Co}_{3} \mathrm{O}_{4} / \mathrm{MoS}_{2}$ showed good performances for both HER and OER. Liu et al. [71] construed an interface between $(\mathrm{Ni}, \mathrm{Fe}) \mathrm{S}_{2}$ nanoboxes and $\mathrm{MoS}_{2}$ nanoarrays $((\mathrm{Ni}, \mathrm{Fe})$ $\mathrm{S}_{2} @ \mathrm{MoS}_{2}$ ) (Fig. 7a), which showed an excellent overall water splitting performance. In-situ Raman results demonstrated that it was easier for the $\mathrm{S}$ edges on the heterostructure to form the $\mathrm{S}-\mathrm{H}_{\text {ads }}$ and the binding strength of intermediates $\left(\mathrm{H}^{*}\right.$ and $\left.\mathrm{OH}^{-*}\right)$ was optimized, leading to a faster reaction kinetics. Kim et al. [72] reported a hierarchically structured $\mathrm{Ni}_{2} \mathrm{P} / \mathrm{MoS}_{2}$ supported by nitrogen-doped carbon for HER. The hierarchical $\mathrm{Ni}_{2} \mathrm{P} / \mathrm{MoS}_{2}$ structure was fabricated via direct phosphidation of $\mathrm{N}$ doped carbon-supported $\mathrm{NiMoS}_{4}$ (Fig. 7b). It was proved that the surface $\mathrm{Ni}_{2} \mathrm{P}$ induced an activation of the $\mathrm{MoS}_{2}$ basal planes, which significantly improved the intrinsic
HER rate on $\mathrm{MoS}_{2}$. Moreover, the heterostructure synergistically increased the electron transfer and enlarged the ECSA, which also enhanced the reaction kinetics. The as-prepared nanomaterials exhibited a platinum-like HER activity with good stability in $0.5 \mathrm{~mol} \mathrm{~L}^{-1} \mathrm{H}_{2} \mathrm{SO}_{4}$. Nguyen et al. [73] engineered a $\mathrm{CoS}_{x} @ \mathrm{Cu}_{2} \mathrm{MoS}_{4}-\mathrm{MoS}_{2} / \mathrm{NSG}$ composite via refluxing the precursors followed by a twostep calcination with controllable heating rate and gas flow rate, the as-prepared material showed a core-shell heterostructure (Fig. 7c, d), which exhibited numerous advantageous physicochemical properties: (i) the $\mathrm{Cu}$ and Mo in $\mathrm{Cu}_{2} \mathrm{MoS}_{4}$ induced the neighboring $\mathrm{S}$ to be effective electrocatalytic active sites, which showed an appropriate oxygen adsorption property and $\mathrm{O}-\mathrm{O}$ bond cleaving ability. (ii) The sulfur in the crystal helped to induce defects that contributed to forming surface oxyhydroxide for oxygen evolution. (iii) The core-shell structure of a

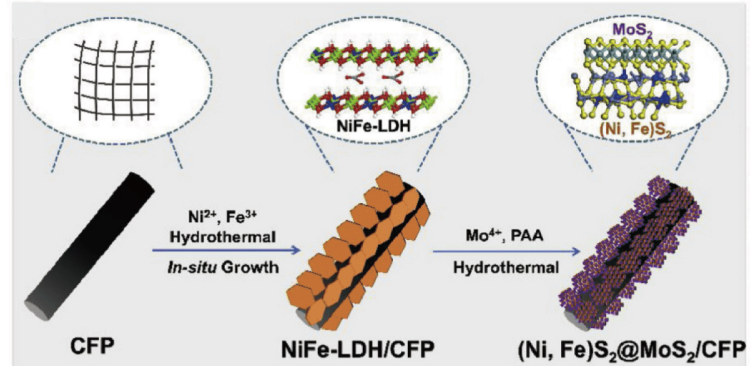

b

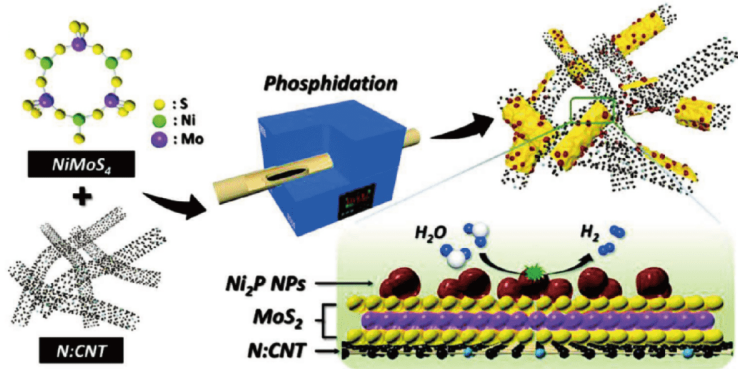

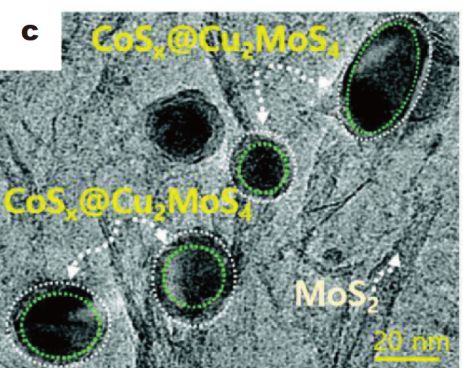
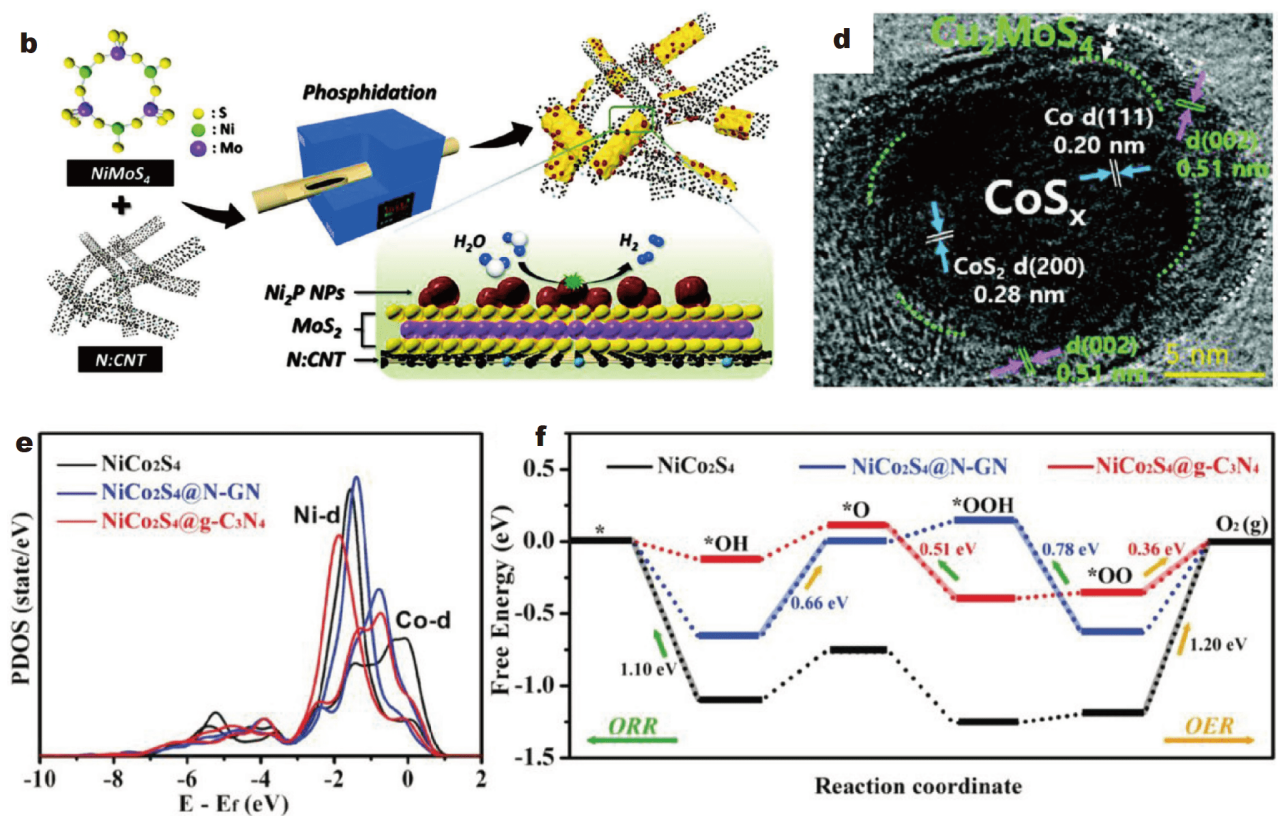

Figure 7 (a) Preparation of (Ni, Fe) $\mathrm{S}_{2} @ \mathrm{MoS}_{2}$ heterostructures. Reprinted with permission [71]. Copyright 2019, Elsevier. (b) Fabrication process of $\mathrm{Ni}_{2} \mathrm{P}$ anchored on $\mathrm{MoS}_{2}$ supported on N:CNT. Reprinted with permission [72]. Copyright 2019, Wiley. (c, d) High-resolution TEM (HRTEM) images of the $\mathrm{CoS}_{x} @ \mathrm{Cu}_{2} \mathrm{MoS}_{4}-\mathrm{MoS}_{2} / \mathrm{NSG}$ hybrid. Reprinted with permission [73]. Copyright 2020, Wiley. (e) Calculated d-band positions of metallic Ni and Co sites and (f) free energy diagrams of ORR and OER processes on different samples. Reprinted with permission [74]. Copyright 2019, Wiley. 
$\mathrm{CoS}_{x} @ \mathrm{Cu}_{2} \mathrm{MoS}_{4}$ exposed more edge-terminated sites that showed excellent intermediate adsorption/desorption properties. (iv) The electronic state of $\mathrm{CoS}_{x} @ \mathrm{Cu}_{2} \mathrm{MoS}_{4}$ was upshifted to the Fermi level, which strengthened the binding between the active sites and reactants. (v) The high conductivity and ECSA realized a good mass and charge transfer ability. Therefore, $\mathrm{CoS}_{x} @ \mathrm{Cu}_{2} \mathrm{MoS}_{4}-\mathrm{MoS}_{2} /$ NSG was simultaneously active in HER, ORR and OER. Moreover, the $\mathrm{CoS}_{x} @ \mathrm{Cu}_{2} \mathrm{MoS}_{4}-\mathrm{MoS}_{2} / \mathrm{NSG}$-based Zn-air battery realized a high cell voltage of ca. $1.44 \mathrm{~V}$ with a power density of $40 \mathrm{~mW} \mathrm{~cm}$ at $58 \mathrm{~mA} \mathrm{~cm}^{-2}$, which outperformed the commercial $\mathrm{Pt} / \mathrm{C}$. Table 2 summarizes the performances of some representative oxide-based electrocatalysts. Han et al. [74] prepared a novel $\mathrm{NiCo}_{2} \mathrm{~S}_{4} /$ graphitic carbon nitride/carbon nanotube $\left(\mathrm{NiCo}_{2} \mathrm{~S}_{4} @ g\right.$ $\mathrm{C}_{3} \mathrm{~N}_{4}$-CNT) composite by a two-step hydrothermal approach and a vacuum filtration process. The CNT support provided a porous network structure that facilitated the charge transfer. Experimental studies revealed the electronic interactions between bimetallic $\mathrm{Ni} / \mathrm{Co}$ active sites and abundant pyridinic- $\mathrm{N}$ species in $\mathrm{g}_{-} \mathrm{C}_{3} \mathrm{~N}_{4}$. Theoretical calculations demonstrated the unique co-activation of bimetallic $\mathrm{Ni} / \mathrm{Co}$ atoms by pyridinic-N species via downshifting their d-band center positions and therefore benefitting the adsorption/desorption features of oxygen intermediates (Fig. 7e). Consequently, $\mathrm{NiCo}_{2} \mathrm{~S}_{4} @ g-\mathrm{C}_{3} \mathrm{~N}_{4}$ CNT showed a high onset potential of $0.87 \mathrm{~V}$ for ORR and surpassed many of the reported TMC-based electrocatalysts (Fig. 7f). Cao et al. [75] fabricated a $\mathrm{NiS}_{2} / \mathrm{CoS}_{2}$ heterostructure as ORR electrocatalyst by an ion hot-injection method. The lattice distortion in the interface induced an electronic modulation, provided abundant electrocatalytic active sites and enhanced the electronic conductivity during the electrochemical process. Consequently, $\mathrm{NiS}_{2} / \mathrm{CoS}_{2}$ displayed a diffusion current density of $4.87 \mathrm{~mA} \mathrm{~cm}^{-2}$, much higher than that of $\mathrm{NiS}_{2}$ and $\mathrm{CoS}_{2}$. Meanwhile, $\mathrm{NiS}_{2} / \mathrm{CoS}_{2}$ showed an onset potential of $0.90 \mathrm{~V}$ and half-wave potential of $0.79 \mathrm{~V}$, which were comparable to those of commercial $\mathrm{Pt} / \mathrm{C}$.

\section{Transition metal selenides}

As congeners, transition metal selenides have similar physiochemical properties with sulfides. Moreover, compared with oxides and sulfides, transition metal selenides exhibit a metallic nature with a faster electron transfer ability, which significantly favors the electrochemical reaction process [76-81]. However, their composite and structural properties are still needed to be improved to compete with noble metal-based electrocatalysts. Various carbon supports have been applied to enhance the exposure of active sites and further increase the conductivity $[82,83]$. Shi et al. [84] prepared polycrystalline $\mathrm{Ni}_{3} \mathrm{Se}_{2}$ arrays on a nickel foam $\left(\mathrm{Ni}_{3} \mathrm{Se}_{2} / \mathrm{NF}\right)$ using a solvothermal method, and the as-prepared $\mathrm{Ni}_{3} \mathrm{Se}_{2}$

Table 2 Comparison of the performances of transition metal sulfide-based electrocatalysts for different applications

\begin{tabular}{|c|c|c|c|c|c|}
\hline Catalyst & Substrate & $\begin{array}{l}\text { Electrolyte } \\
\text { /reaction }\end{array}$ & $\begin{array}{l}\text { Overpotential } \\
(\mathrm{mV}) @ \mathrm{~mA} \mathrm{~cm}{ }^{-2}\end{array}$ & $\begin{array}{c}\text { Tafel slope } \\
\left(\mathrm{mV} \mathrm{decade}^{-1}\right)\end{array}$ & $\begin{array}{c}\text { Stability } \\
\left(\mathrm{mA} \mathrm{cm}{ }^{-2} @ \mathrm{~h}\right)\end{array}$ \\
\hline MoS-CoS-Zn [58] & Glassy carbon & $0.5 \mathrm{~mol} \mathrm{~L}^{-1} \mathrm{H}_{2} \mathrm{SO}_{4} / \mathrm{HER}$ & $72.6 @ 10$ & 37.6 & $10 @ 60$ \\
\hline $\mathrm{Co}_{9} \mathrm{~S}_{8} / \mathrm{NSG}-8[61]$ & Glassy carbon & $1.0 \mathrm{~mol} \mathrm{~L}^{-1} \mathrm{KOH} / \mathrm{OER}$ & 260@10 & 55 & 2000 cycles \\
\hline $\mathrm{Ni}_{3} \mathrm{~S}_{2}$ NTFs [65] & $\mathrm{Ni}$ foam & $1.0 \mathrm{~mol} \mathrm{~L}^{-1} \mathrm{NaOH} / \mathrm{HER}$ & 177@20 & 75.7 & $10 @ 30$ \\
\hline $\mathrm{Ni}_{3} \mathrm{~S}_{2}$ NTFs [65] & Ni foam & $1.0 \mathrm{~mol} \mathrm{~L}^{-1} \mathrm{NaOH} / \mathrm{OER}$ & $319 @ 20$ & 101.2 & $10 @ 30$ \\
\hline $\mathrm{a}-\mathrm{MoS}_{x}[66]$ & & $0.5 \mathrm{~mol} \mathrm{~L}^{-1} \mathrm{H}_{2} \mathrm{SO}_{4} / \mathrm{HER}$ & 145@10 & 40 & 1000 cycles \\
\hline CoNiFe-S MNs [67] & Carbon fiber paper & $1.0 \mathrm{~mol} \mathrm{~L}^{-1} \mathrm{KOH} / \mathrm{OER}$ & 199@10 & 50.1 & 1.54 V@50 \\
\hline CoNiFe-S MNs [67] & RRDE & $0.1 \mathrm{~mol} \mathrm{~L}^{-1} \mathrm{KOH} / \mathrm{ORR}$ & $E_{1 / 2}=0.78 \mathrm{~V}$ & & 10 \\
\hline $\mathrm{NiMo}_{3} \mathrm{~S}_{4} / \mathrm{CTs}[68]$ & Carbon textiles & $0.5 \mathrm{~mol} \mathrm{~L}^{-1} \mathrm{H}_{2} \mathrm{SO}_{4} / \mathrm{HER}$ & 124@10 & 46.2 & $72 \mathrm{~h}$ \\
\hline $\mathrm{Co}_{3} \mathrm{O}_{4} / \mathrm{MoS}_{2}[70]$ & Ni foam & $1.0 \mathrm{~mol} \mathrm{~L}^{-1} \mathrm{KOH} / \mathrm{OER}$ & $230 @ 20$ & 45 & 20@13 \\
\hline $\mathrm{Co}_{3} \mathrm{O}_{4} / \mathrm{MoS}_{2}[70]$ & Ni foam & $1.0 \mathrm{~mol} \mathrm{~L}^{-1} \mathrm{KOH} / \mathrm{HER}$ & 205@10 & 98 & $10 @ 14$ \\
\hline$(\mathrm{Ni}, \mathrm{Fe}) \mathrm{S}_{2} @ \mathrm{MoS}_{2}[71]$ & Carbon fiber paper & $1.0 \mathrm{~mol} \mathrm{~L}^{-1} \mathrm{KOH} / \mathrm{HER}$ & 130@10 & 101.22 & $10 @ 44$ \\
\hline$(\mathrm{Ni}, \mathrm{Fe}) \mathrm{S}_{2} @ \mathrm{MoS}_{2}[71]$ & Carbon fiber paper & $1.0 \mathrm{~mol} \mathrm{~L}^{-1} \mathrm{KOH} / \mathrm{OER}$ & $270 @ 10$ & 43.21 & 1.52-1.55 V@44 \\
\hline $\mathrm{Ni}_{2} \mathrm{P} / \mathrm{MoS}_{2} / \mathrm{N}: \mathrm{CNT}[72]$ & Glassy carbon & $0.5 \mathrm{~mol} \mathrm{~L}^{-1} \mathrm{H}_{2} \mathrm{SO}_{4} / \mathrm{HER}$ & 93.9@10 & 57.8 & 3000 cycles \\
\hline $\mathrm{CoS}_{x} @ \mathrm{Cu}_{2} \mathrm{MoS}_{4}-\mathrm{MoS}_{2} / \mathrm{NSG}$ [73] & Carbon paper & $0.1 \mathrm{~mol} \mathrm{~L}^{-1} \mathrm{KOH} / \mathrm{HER}$ & 118.1@10 & 41.1 & $10 @ 33$ \\
\hline $\mathrm{CoS}_{x} @ \mathrm{Cu}_{2} \mathrm{MoS}_{4}-\mathrm{MoS}_{2} / \mathrm{NSG}$ [73] & Carbon paper & $0.1 \mathrm{~mol} \mathrm{~L}^{-1} \mathrm{KOH} / \mathrm{OER}$ & 351.4@10 & 61.5 & $10 @ 33$ \\
\hline $\mathrm{CoS}_{x} @ \mathrm{Cu}_{2} \mathrm{MoS}_{4}-\mathrm{MoS}_{2} / \mathrm{NSG}$ [73] & RRDE & $0.1 \mathrm{~mol} \mathrm{~L}^{-1} \mathrm{KOH} / \mathrm{ORR}$ & $E_{1 / 2}=0.89 \mathrm{~V}$ & 53.5 & $16.4 \mathrm{~h}$ \\
\hline
\end{tabular}

RRDE: rotating ring-disk electrode. 
nanowires exposed abundant gain boundaries on the surface. The gain boundaries and the surface-rough nanowire morphology of the selenides provided abundant catalytic sites during reactions. Moreover, the adsorption and transport properties of reactants were significantly enhanced owing to the structural properties. The $\mathrm{Ni}_{3} \mathrm{Se}_{2} /$ NF showed efficient overall water splitting performance. Wang et al. [85] prepared coral-like $\mathrm{NiSe}_{2} / \mathrm{g}-\mathrm{C}_{3} \mathrm{~N}_{4}$ hybride using a hydrothermal method, where the $\mathrm{NiSe}_{2}$ particles were uniformly affixed on the layers of graphitic carbon nitride. The structural properties contributed to facilitating the charge transfer and enhancing the intrinsic activity of $\mathrm{NiSe}_{2}$. The material showed efficient OER activity (an overpotential of $290 \mathrm{mV}$ at $40 \mathrm{~mA} \mathrm{~cm}{ }^{-2}$ ). Wang et al. [86] reported a CS@CNC NAs/CC nanomaterial using a co-precipitation method followed by selenylation in inert atmosphere (Fig. 8a). Owing to the carbon framework, the $\mathrm{CoSe}_{2}$ nanoparticles were confined in the cobalt-nitrogen-doped carbon layers with good dispersion. The framework not only enabled fast charge and mass transfer, but also helped to expose more active sites for the reaction. Meanwhile, the adsorption properties of the intermediates on $\mathrm{CoSe}_{2}$ were also optimized, and the agglomeration of $\mathrm{CoSe}_{2}$ was inhibited. As a result, the CS@CNC NAs/CC required only $84 \mathrm{mV}$ to reach $10 \mathrm{~mA} \mathrm{~cm}^{-2}$ with a 72-h stability.

Tuning the phase of selenides from $2 \mathrm{H}$ to $1 \mathrm{~T}$ can significantly increase the conductivity and expose more active sites [87]. Deng et al. [88] first loaded $\mathrm{MoSe}_{2}$ NSs onto a nitrogen-doped porous carbon support and then intercalated $\mathrm{PO}_{4}^{3-}$ into the $2 \mathrm{H} \mathrm{MoSe}$, which finally formed a carbon-supported bi-phase-coexisting $\mathrm{MoSe}_{2}$ hybrid ((1T-2H)- $\left.\mathrm{MoSe}_{2} / \mathrm{N}-\mathrm{MSC}\right)$. The highly conductive $\mathrm{N}$-MSC support greatly reduced the charge resistance and the $2 \mathrm{D}$ morphology of $1 \mathrm{~T} \mathrm{MoSe}_{2}$ increased the exposed active sites. Meanwhile, the decreased bandgap of $1 \mathrm{~T}$ $\mathrm{MoSe}_{2}$ led to a higher conductivity (Fig. 8b, c). Moreover, the DFT calculations demonstrated a reduced HER energy barrier and favorable hydrogen desorption of hydrogen on the bi-phase-MoSe $\mathrm{M}_{2}$ (Fig. 8d). Benefiting from these unique advantages, the $\mathrm{P}-\mathrm{MoSe}_{2} / \mathrm{N}-\mathrm{MSC}$ exhibited a high HER activity $\left(-126 \mathrm{mV}\right.$ at $\left.10 \mathrm{~mA} \mathrm{~cm}^{-2}\right)$ with high durability. Deng et al. [89] first prepared TiC-C arrays via a facile CVD method, and then they loaded 1T-MoSe NSs onto TiC-C via a hydrothermal method. After Ar thermal treatment and $\mathrm{NH}_{3}$ annealing, a nitrogen-doped $\mathrm{MoSe}_{2} / \mathrm{TiC}-\mathrm{C}$ hierachical material with phase and morphology modulation was fabricated. From the results of theoretical calculation, the incorporation of nitrogen not only led to a narrow band gap of the pristine molybdenum selenide, but also induced a phase transformation from $2 \mathrm{H}$ to $1 \mathrm{~T} \mathrm{MoSe}_{2}$. The DFT calculations revealed that the $\mathrm{N}$-doped $\mathrm{MoSe}_{2}$ exhibited a lower energy for $\mathrm{H}_{2}$ formation and higher ability for $\mathrm{H}_{2}$ desorption compared with $1 \mathrm{~T}$ and $2 \mathrm{H} \mathrm{MoSe}$. Besides, the highly conductive TiC-C substrate significantly reduced the charge transfer resistance and increased the exposure of catalytic sites, which further promoted the reaction kinetics. The $\mathrm{MoSe}_{2} /$
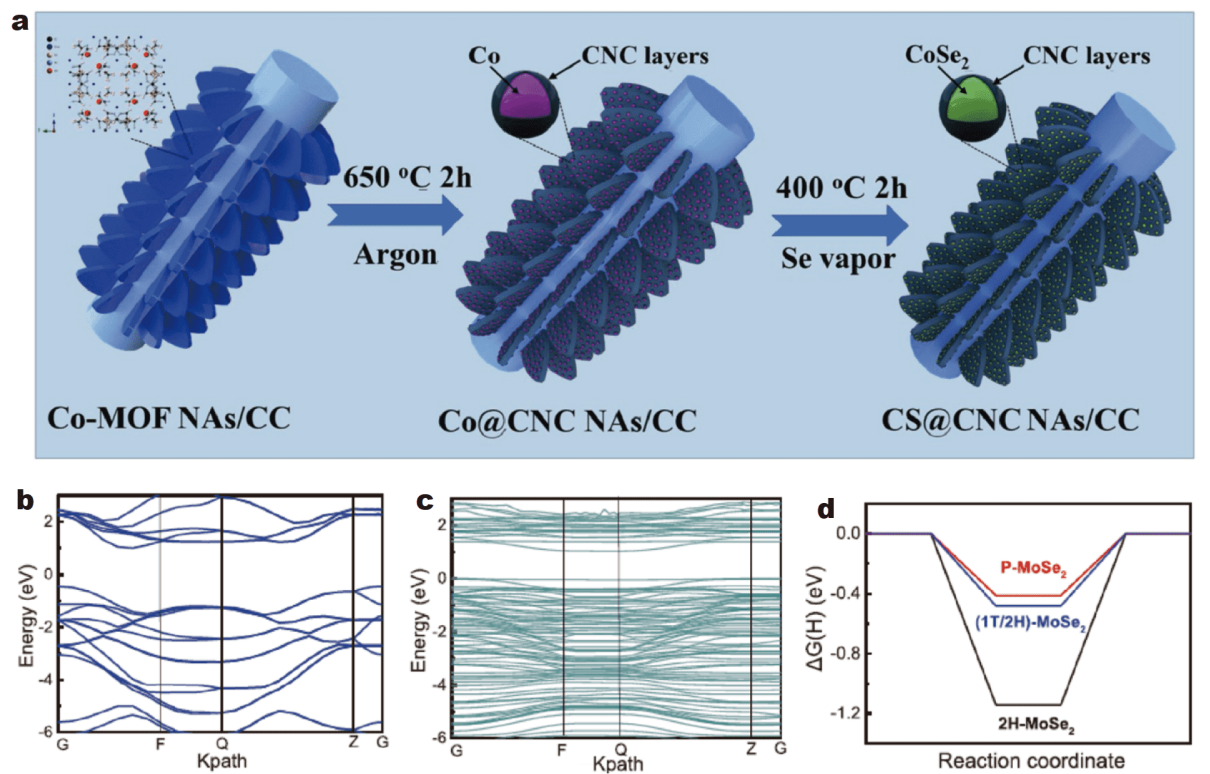

Figure 8 (a) Fabrication process of CS@CNC NAs/CC. Reprinted with permission [86]. Copyright 2019, Elsevier. (b, c) Calculated band structures of $2 \mathrm{H}-\mathrm{MoSe}_{2}$ and P-MoSe ${ }_{2}$, respectively, (d) HER free energy diagrams of different selenides. Reprinted with permission [88]. Copyright 2019, Wiley. 
Table 3 Comparison of the performances of transition metal selenide-based electrocatalysts for different applications

\begin{tabular}{|c|c|c|c|c|c|}
\hline Catalyst & Substrate & $\begin{array}{l}\text { Electrolyte } \\
\text { /reaction }\end{array}$ & $\begin{array}{l}\text { Overpotential } \\
(\mathrm{mV}) @ \mathrm{~mA} \mathrm{~cm}^{-2}\end{array}$ & $\begin{array}{c}\text { Tafel slope } \\
\left(\mathrm{mV} \text { decade }{ }^{-1}\right)\end{array}$ & $\begin{array}{c}\text { Stability } \\
\left.\text { (mA cm }{ }^{-2} @ h\right)\end{array}$ \\
\hline $\begin{array}{c}\mathrm{CoSe}_{2}^{(400)}{ }_{-} \\
\mathrm{NC}-800[76]\end{array}$ & Glassy carbon & $1.0 \mathrm{~mol} \mathrm{~L}^{-1} \mathrm{KOH} / \mathrm{HER}$ & 234@10 & 95 & 45@13.8 \\
\hline Meso-CoSSe-12h [77] & Glassy carbon & $0.5 \mathrm{~mol} \mathrm{~L}^{-1} \mathrm{H}_{2} \mathrm{SO}_{4} / \mathrm{HER}$ & 110@10 & 52 & $100 @ 25$ \\
\hline Fe7.4\%-NiSe [79] & $\mathrm{Ni}$ foam & $1.0 \mathrm{~mol} \mathrm{~L}^{-1} \mathrm{KOH} / \mathrm{OER}$ & 231@50 & 43 & 0.217 V@22 \\
\hline $\mathrm{SnSe}_{2} / \mathrm{GNS}[81]$ & Graphite NSs & $0.5 \mathrm{~mol} \mathrm{~L}^{-1} \mathrm{H}_{2} \mathrm{SO}_{4} / \mathrm{HER}$ & 382@10 & 109.3 & 5000 cycles \\
\hline $\mathrm{Ni}_{3} \mathrm{Se}_{2} / \mathrm{NF}[84]$ & Ni foam & $1.0 \mathrm{~mol} \mathrm{~L}^{-1} \mathrm{KOH} / \mathrm{OER}$ & 320@100 & 58 & 6000 cycles \\
\hline $\mathrm{Ni}_{3} \mathrm{Se}_{2} / \mathrm{NF}[84]$ & $\mathrm{Ni}$ foam & $1.0 \mathrm{~mol} \mathrm{~L}^{-1} \mathrm{KOH} / \mathrm{HER}$ & 95@50 & 67 & 6000 cycles \\
\hline $\mathrm{NiSe}_{2} / g-\mathrm{C}_{3} \mathrm{~N}_{4}[85]$ & Ni foam & $1.0 \mathrm{~mol} \mathrm{~L}^{-1} \mathrm{KOH} / \mathrm{OER}$ & 290@40 & 143 & 1.42 V@10 \\
\hline CS@CNC NAs/CC [86] & Carbon cloth & $0.5 \mathrm{~mol} \mathrm{~L}^{-1} \mathrm{H}_{2} \mathrm{SO}_{4} / \mathrm{HER}$ & 84@10 & 38 & 2000 cycles \\
\hline $\mathrm{P}-\mathrm{MoSe}_{2} / \mathrm{N}-\mathrm{MSC}[88]$ & Carbon cloth & $0.5 \mathrm{~mol} \mathrm{~L}^{-1} \mathrm{H}_{2} \mathrm{SO}_{4} / \mathrm{HER}$ & 126@10 & 51 & 10@10 \\
\hline $\mathrm{N}-\mathrm{MoSe}_{2} / \mathrm{TiC}-\mathrm{C}[89]$ & TiC-C & $0.5 \mathrm{~mol} \mathrm{~L}^{-1} \mathrm{H}_{2} \mathrm{SO}_{4} / \mathrm{HER}$ & 106@10 & 32 & 100@4 \\
\hline Co-Se1 [92] & Co foil & $1.0 \mathrm{~mol} \mathrm{~L}^{-1} \mathrm{KOH} / \mathrm{OER}$ & 280@100 & 40.4 & 2000 cycles \\
\hline $\mathrm{Co}-\mathrm{Se} 4[92]$ & Co foil & $1.0 \mathrm{~mol} \mathrm{~L}^{-1} \mathrm{KOH} / \mathrm{HER}$ & 268@100 & 61.4 & 2000 cycles \\
\hline
\end{tabular}

TiC-C exhibited an excellent HER performance $(137 \mathrm{mV}$ at $100 \mathrm{~mA} \mathrm{~cm}{ }^{-2}$ ) in $0.5 \mathrm{~mol} \mathrm{~L}^{-1} \mathrm{H}_{2} \mathrm{SO}_{4}$. Zhang et al. [90] loaded $1 \mathrm{~T}-\mathrm{MoSe}_{2}$ NSs onto the NiSe substrates using a hydrothermal method, which formed a 3D core-shell heterostructure with numerous metallic $1 \mathrm{~T}-\mathrm{MoSe}_{2}$ on the surface $\left(1 \mathrm{~T}-\mathrm{MoSe}_{2} / \mathrm{NiSe}\right)$. During the preparation, the electron transfered from NiSe to $\mathrm{MoSe}_{2}$, inducing the transformation of $\mathrm{MoSe}_{2}$ from 2H- to 1T-phase. The edges of $1 \mathrm{~T}-\mathrm{MoSe}_{2}$ were highly active sites for HER and the substrate NiSe helped to facilitate the water dissociation. Meanwhile, the 3D conductive heterostructure exposed more catalytic sites, and the charge and mass transfer were facilitated during the reaction. Moreover, the strong interaction between the two selenides contributed to maintaining the 1T-phase of $\mathrm{MoSe}_{2}$. As a result, the $1 \mathrm{~T}-\mathrm{MoSe}_{2} / \mathrm{NiSe}$ showed high HER activity with high stability.

In addition, constructing heterostructure and doping are also applied for synthesizing novel selenides [91]. Zhao et al. [92] synthesized a 3D cobalt selenide electrocatalyst composed of CoSe and $\mathrm{Co}_{9} \mathrm{Se}_{8}$ via a facile onestep selenization of Co foil with Se powder in a vacuumsealed ampoule. By manipulating the ratio of $\mathrm{Co} / \mathrm{Se}$ in the precursor, the electronic state of Co species in the products was regulated and the application of the catalyst would go from OER to HER. The higher charge-stated Co sites promoted the OER kinetics, which was attributed to the easier adsorption and conversion of $\mathrm{OH}^{-}$with the presence of more high-valent cobalt. Meanwhile, the less $\mathrm{Se}^{\delta-}$ sites on the surface could also favor the OER kinetics. While the HER process preferred the lower charge state of
Co species, which could be beneficial to the enhanced electron transfer and more exposed active sites. Moreover, the high ratio of surface $\mathrm{Se}^{\delta-}$ facilitated the adsorption/desorption of proton and therefore facilitated HER. Yuan et al. [93] fabricated a $\mathrm{CoSe} / \mathrm{MoSe}_{2}$ nanomaterial using the pyrolysis and selenylation of $\mathrm{Mo}$, Cobased MOFs, which were composed of CoSe nanoparticles and $\mathrm{MoSe}_{2}$ nanolamellas. The strong interaction between CoSe and $\mathrm{MoSe}_{2}$ facilitated the electron transfer and upshifted the d-band center of the selenides, and therefore the adsorption of reactants $\left(\mathrm{OH}^{-}\right)$was reduced. Meanwhile, more defects were formed due to the heterostructure and provided more adsorption sites for $\mathrm{OH}^{-}$. Besides, the well dispersed nano-sized selenides provided more OER sites. Therefore, the CoSe/ $\mathrm{MoSe}_{2}$ required an overpoetntial of only $262 \mathrm{mV}$ to reach $10 \mathrm{~mA} \mathrm{~cm}^{-2}$ with 20-h stability. Jing et al. [94] prepared a $\mathrm{Fe}_{3} \mathrm{Se}_{4} / \mathrm{FeSe} /$ NPGC heterostructure via a simple one-pot reduction method (carbonizing the cornstalk cores immersed by $\mathrm{Fe}$ and Se precursors under $\mathrm{N}_{2}$ protection). The hybride exhibited a porous nanostructure with numerous channels, which significantly promoted the oxygen diffusion and exposed more catalytic sites. The heterojunctions and the carbon support enabled a high charge transfer rate during the reaction. Moreover, the well dispersed selenides and the $\mathrm{N}$-dpoed carbon defects acted as active ORR sites. The $\mathrm{Fe}_{3} \mathrm{Se}_{4} / \mathrm{FeSe} / \mathrm{NPGCs}$ exhibited efficient ORR performances in $50 \mathrm{mmol} \mathrm{L}^{-1} \mathrm{PBS}$ electrolyte. Wang et al. [95] prepared spinel $\mathrm{CoIn}_{2} \mathrm{Se}_{4} \mathrm{NSs}$, where $\mathrm{Co}^{2+}$ occupied the tetrahedral and $\mathrm{In}^{3+}$ occupied the octahedral site of the crystal structure via fast selenylation of In and 
Co precursors by hot-injection of cation solution into anion (Se) solution. The $\mathrm{CoIn}_{2} \mathrm{Se}_{4}$ NSs featured abundant active sites and ideal charge transfer ability for boosting the reaction kinetics. Moreover, the DFT calculations confirmed that the reaction pathway on the surface of spinel selenide can be significantly facilitated. As a result, the $\mathrm{CoIn}_{2} \mathrm{Se}_{4}$ catalyst showed a remarkable ORR performance in the alkaline electrolyte. Moreover, the flexible zinc-air battery using $\mathrm{CoIn}_{2} \mathrm{Se}_{4}$ as the air cathode showed a high open-circuit voltage of $1.37 \mathrm{~V}$, a large specific capacity of $733 \mathrm{~mA} \mathrm{hg}_{\mathrm{Zn}}^{-1}$, and an energy density of $931 \mathrm{~W} \mathrm{~h} \mathrm{~kg}^{-1}$.

\section{Transition metal phosphides}

Transition metal phosphides have been widely explored due to their low cost and impressive HER performances, owing to the electronic features of $\mathrm{P}$ that can extract electrons from the neighboring metals [24]. As a result, the $\mathrm{P}$ sites prefer to attract the protons in the electrolyte, contributing to a suitable bonding between the catalytic sites and the intermediates/products. In addition, researches about phosphides for electrocatalytic oxygen reactions have been also reported recently, extending the applications of phosphides in energy conversion [96100]. Tuning the crystal structure via the strain effect has been proved to be an effective way to improve the activity. Li et al. [101] proposed an iron phosphide material modified by carbon for OER, where the carbon induced a tensile strain in $\mathrm{FeP}_{2}$ crystal during the preparation (Fig. 9a, b). The strain effect of $\mathrm{FeP}_{2}$ led to an electron redistribution in the hydroxyl when adsorbed on the catalytic site, which led to strengthened adsorption of the intermediates during the reaction. The DFT calculations demonstrated that the energy barrier of the ratedetermining step was reduced owing to the carboncovered strained $\mathrm{FeP}_{2}$ crystal. Meanwhile, the incorporation of carbon improved the chemical stability of $\mathrm{FeP}_{2}$ nanoparticles and reduced the charge transfer resistance. Therefore, the catalyst showed an outstanding OER performance.

Dopants can also alter the adsorption properties of the intermediates on phosphides [102]. Cao et al. [103] fabricated a $\mathrm{N}$-doped carbon-covered $\mathrm{Ni}$-Co phosphide material supported on nickel foam $\left(\mathrm{Ni}_{x} \mathrm{Co}_{2-x} \mathrm{P} @ \mathrm{NC} \mathrm{NA} /\right.$ $\mathrm{NF}$ ). They first fabricated a series of Ni-Co layered hydroxides on $\mathrm{Ni}$ foam through a hydrothermal process,
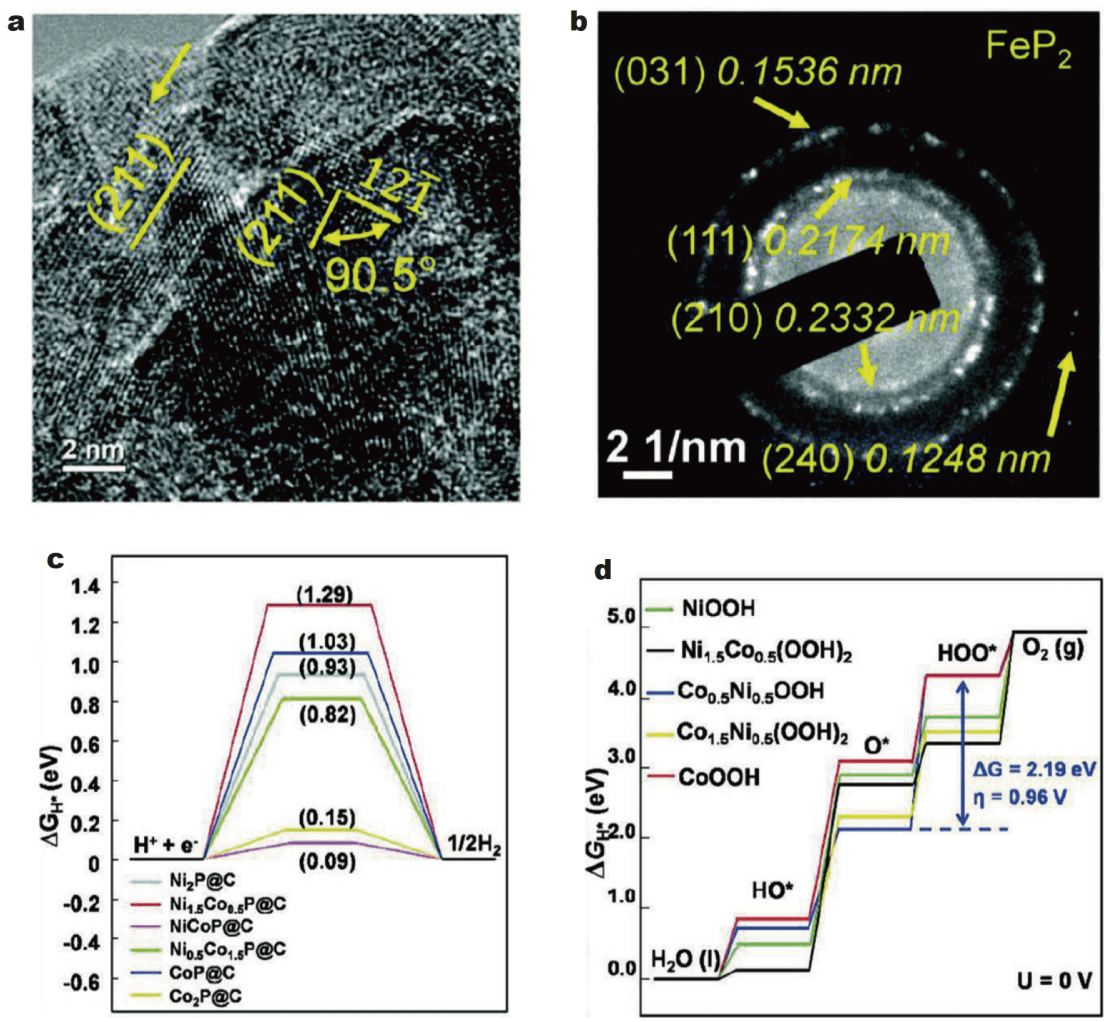

Figure 9 (a, b) HRTEM and the corresponding SAED pattern of $\mathrm{FeP}_{2}$. Reprinted with permission [101]. Copyright 2020, Wiley. (c) HER free energy diagram of different catalysts, (d) OER free energy diagrams of different catalysts under 0 V. Reprinted with permission [103]. Copyright 2019, Wiley. 
and then a phosphidation treatment under $\mathrm{N}_{2}$ was carried out to form various $\mathrm{NixCo}_{2-x} \mathrm{P}$ nanostructures embedded in $\mathrm{N}$-doped carbon matrix $\left(\mathrm{Ni}_{x} \mathrm{Co}_{2-x} \mathrm{P} @ \mathrm{NC} \mathrm{NA} / \mathrm{NF}\right) . \mathrm{Via}$ tuning the molar ratio of $\mathrm{Ni} / \mathrm{Co}$ salts, both the phase and morphology of $\mathrm{Ni}_{x} \mathrm{Co}_{2-x} \mathrm{P}$ were tuned and embedded in carbon matrix. The designed 3D morphology of the hybrid material not only provided a stable structure, but also improved the electron/mass transfer capability. Moreover, the unique nanostructure of the material enlarged the ECSA, leading to increased exposure of reaction active sites. The DFT calculations revealed that both the $\mathrm{Ni} / \mathrm{Co}$ ratio and surface played critical roles in determining the reaction energy barrier: for HER, the $\Delta G_{\mathrm{H}}{ }^{*}$ on NiCoP@C with a carbon shell on NiCoP was close to zero and therefore suitable for HER (Fig. 9c). For OER, the surface metal oxyhydroxides were responsible for the reaction activity, and the energy barrier of the rate-determining step (formation of $\mathrm{O}^{*}$ ) on $\mathrm{Ni}_{0.5} \mathrm{Co}_{0.5} \mathrm{OOH}$ was the lowest among different phosphides, which facilitated the OER kinetics (Fig. 9d). Therefore, the $\mathrm{Ni}_{0.5} \mathrm{Co}_{0.5} \mathrm{P} @ \mathrm{NC}$ $\mathrm{NA} / \mathrm{NF}$ required only $1.56 \mathrm{~V}$ to reach $20 \mathrm{~mA} \mathrm{~cm}^{-2}$ for water splitting. Lv et al. [104] used graphene oxide to control the crystal growth and synthesized a hybrid 2D ultrathin Ni-Co phosphide with high porosity (Fig. 10ac). $\mathrm{NiCo}(\mathrm{OH})_{x}$ was firstly loaded onto graphene oxide and NiCoP NSs were obtained after the calcination and phosphorization. In the $\mathrm{NiCoP}$, electrons migrated from metal ions to $\mathrm{P}$, leading to a higher valance state of $\mathrm{Co}$ and $\mathrm{Ni}$, which favored the formation of surface $\mathrm{NiOOH}$ or $\mathrm{CoOOH}$ for OER. Meanwhile, the $\mathrm{P}$ atoms with higher electron density showed a high proton-capture ability during the reaction process. The DFT calculations demonstrated that the energy barriers of both HER and OER were significantly lowered on the one-layer NiCoP than the bulk NiCoP, and the ultrathin NiCoP exhibited a metallic property with high carrier density. Besides, the $2 \mathrm{D}$ and porous structure provided more active site for the reaction. The NiCoP NSs required only 34.3 and $245.0 \mathrm{mV}$ to reach $10 \mathrm{~mA} \mathrm{~cm}^{-2}$ for HER and OER, respectively. Wu et al. [105] designed $\mathrm{N}$-doped carbon nanotube (NCNT)-wrapped $\mathrm{Cr}$-doped FeNi-P nanomaterial (Cr-doped FeNi-P/NCNT) for HER and OER using a one-step annealing method. Among all compositions, both the NCNT and $\mathrm{Cr}$ dopant contributed to lowering the electron transfer resistance. Besides, the NCNT matrix helped to maintain the stability, and the introduction of $\mathrm{Cr}$ increased the exposure of catalytic sites. According to the DFT calculations, the $\mathrm{Cr}$ doping enhanced the adsorption of $\mathrm{H}_{2} \mathrm{O}$ and $\mathrm{OH}^{-}$and desorption of $\mathrm{H}_{2}$, which promoted the HER pathway (Fig. 10d). As for OER, the rate-determining step changed from the formation of $\mathrm{OOH}^{*}$ to the formation of $\mathrm{O}_{2}$ with lower energy barrier after $\mathrm{Cr}$ doping, and the theoretical potential also decreased (Fig. 10e). The as-prepared Cr-doped FeNi-P/ NCN showed excellent performances for both OER and HER.

Hybrid materials have been proved to show an enhanced activity owing to the synergetic effect [106]. Yu et
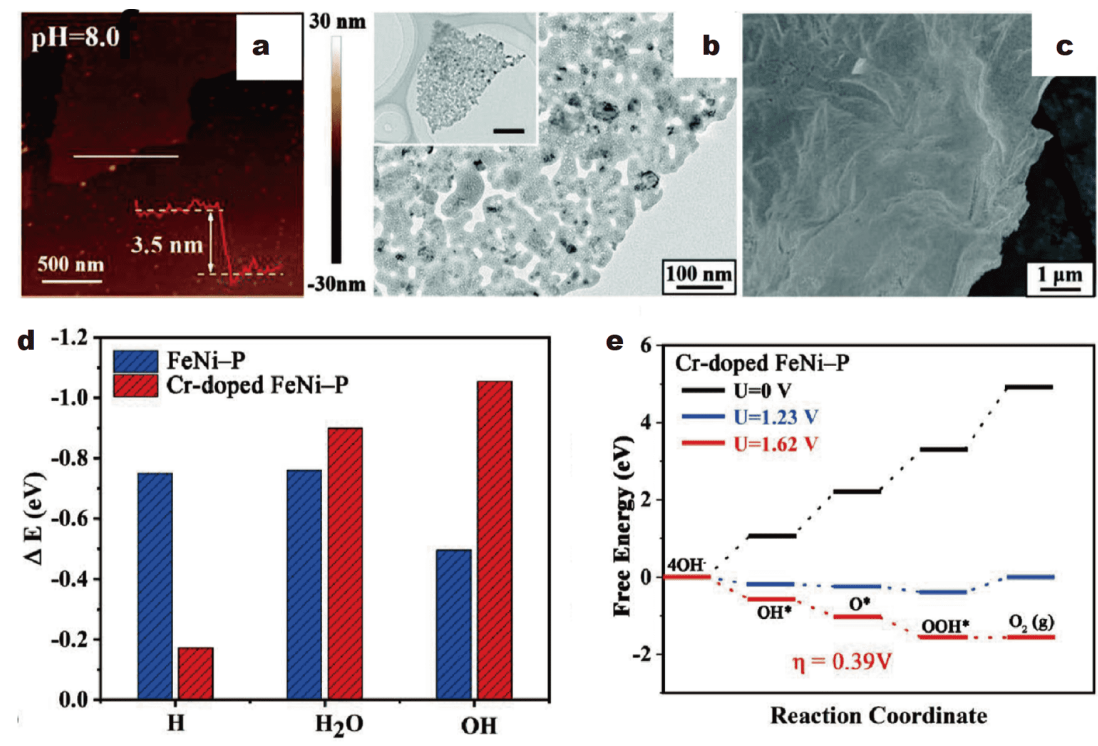

Figure 10 (a-c) AFM image, low-magnification TEM images and SEM image of ultrathin NiCoP NSs. Reprinted with permission [104]. Copyright 2020, Wiley. (d) Adsorption energies of different intermediates on different phosphides, (e) OER free energy profiles of different phosphides. Reprinted with permission [105]. Copyright 2019, Wiley. 


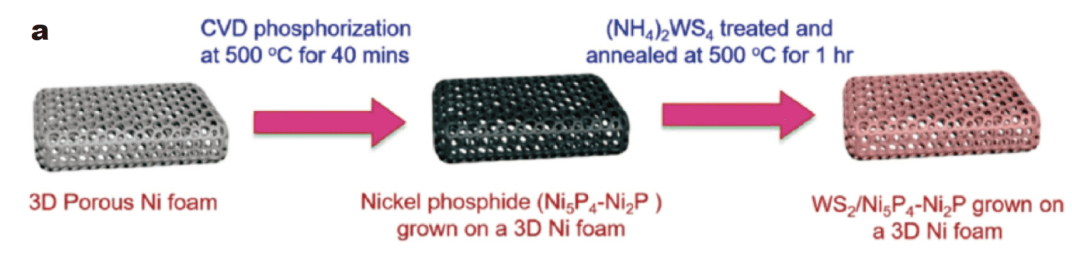

b

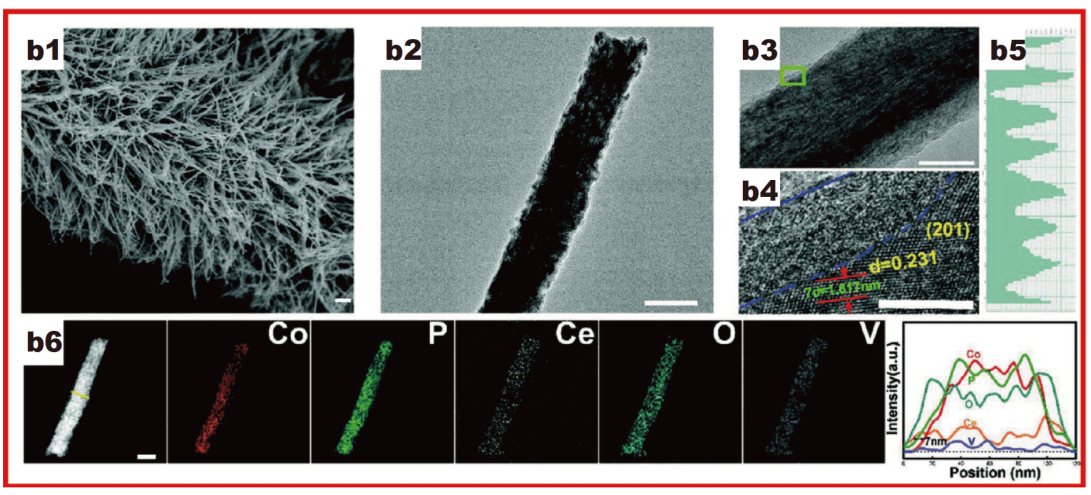

Figure 11 (a) Fabrication of $\mathrm{WS}_{2} / \mathrm{Ni}_{5} \mathrm{P}_{4}-\mathrm{Ni}_{2} \mathrm{P}$ hybrid on Ni foam. Reprinted with permission [107]. Copyright 2019, Elsevier. (b) Morphology and element distribution of V-CoP@a- $\mathrm{CeO}_{2}$. Scale bars in (b1), (b2), (b3), (b4) and (b6), are $1 \mu \mathrm{m}, 100 \mathrm{~nm}, 50 \mathrm{~nm}, 5 \mathrm{~nm}$ and $100 \mathrm{~nm}$, respectively. Reprinted with permission [108]. Copyright 2020, Wiley.

al. [107] developed the hybridized $\mathrm{WS}_{2} / \mathrm{Ni}_{5} \mathrm{P}_{4}-\mathrm{Ni}_{2} \mathrm{P}$ as HER electrocatalysts through a thermal process (Fig. 11a). $\mathrm{WS}_{2(1-x)} \mathrm{P}_{2 x}$ was detected on the surface of the $\mathrm{WS}_{2} / \mathrm{Ni}_{5} \mathrm{P}_{4^{-}}$ $\mathrm{Ni}_{2} \mathrm{P}$, leading to the electron density variation. The combination of $\mathrm{WS}_{2}$ and $\mathrm{Ni}_{5} \mathrm{P}_{4}-\mathrm{Ni}_{2} \mathrm{P}$ effectively increased the ECSA and the active sites for HER, and the electron transportation from $\mathrm{Ni}_{5} \mathrm{P}_{4}-\mathrm{Ni}_{2} \mathrm{P}$ to $\mathrm{WS}_{2}$ enhanced the electrochemical reaction activity. According to the DFT calculation, the new active sites arose with the $\mathrm{P}$ and $\mathrm{Ni}$ doping into the $\mathrm{WS}_{2}$. The calculated Fermi levels of $\mathrm{NiP}_{2}$, $\mathrm{Ni}_{5} \mathrm{P}_{4}$ and $\mathrm{WS}_{2}$ were $-4.661,-4.953$ and $-5.462 \mathrm{eV}$, respectively, which implied the electrons flowed from $\mathrm{Ni}_{5} \mathrm{P}_{4}-\mathrm{Ni}_{2} \mathrm{P}$ to $\mathrm{WS}_{2}$ and facilitated the HER. Yang et al. [108] reported a hierarchical vanadium-cobalt phosphide material covered by amorphous cerium oxide (V-CoP@a$\mathrm{CeO}_{2}$ ), which was supported by carbon cloth for HER and OER (Fig. 11b). The material was prepared through a three-step procedure, including the hydrothermal process, phosphorization, and final electrodeposition. Theoretical calculations demonstrated that there was a synergistic effect between $\mathrm{V}$ and $\mathrm{CeO}_{2}$, which altered the electron redistribution in the material and increased the electron density of Co sites. As a result, the hydrogen adsorption on Co sites was optimized and the reaction energy barrier was reduced. Besides, the Co sites with lower valance state favored the formation of surface $\mathrm{CoOOH}$, which was the actual OER site. Moreover, the charge resistance was sharply decreased after the combi- nation of the hybrid metal phosphide and the amorphous ceria, leading to an enhanced electron transfer during the reaction process. The V-CoP@a- $\mathrm{CeO}_{2}$ only needed a voltage of $1.56 \mathrm{~V}$ to reach $10 \mathrm{~mA} \mathrm{~cm}^{-2}$. Boppella et al. [109] prepared a nitrogen-doped carbon-supported 2D $\mathrm{CoP} / \mathrm{NiCoP}$ composite material using the combination of co-precipitation, electrostatic self-assembly, and phosphorization. The synergy between the two metal phosphide components led to an altered electron distribution, which reduced the energy barrier and facilitated the reaction kinetics. The interface between $\mathrm{CoP}$ and $\mathrm{NiCoP}$ created more adsorption sites for the reactants. The heterostructure and the 2D morphology of the nanomaterial helped to expose more catalytic sites. The strong coupling between the metal phosphides and the carbon support helped to reduce the electron transfer resistance. Therefore, the $\mathrm{CoP} / \mathrm{NiCoP}$ composite exhibited an efficient HER performances in a wide $\mathrm{pH}$ range. Zhang et al. [110] developed a CoP NS combined with CNTs (CoP NS/ CNTs) for HER using a hydrothermal synthesis. The CNT support inhibited the agglomeration of CoP and therefore more active sites were exposed. Meanwhile, owing to the strong interaction between $\mathrm{CoP}$ and CNTs, the charge-transfer capability of CoP NS/CNTs was significantly enhanced, leading to a more rapid kinetics for HER. Besides, the CNTs favored the wettability of CoP NS and improved the interaction between the active site and water molecule, which significantly promoted the 
water dissociation. With all enhanced properties mentioned above, the CoP NS/CNTs only required an overpotential of $68 \mathrm{mV}$ to reach $10 \mathrm{~mA} \mathrm{~cm}^{-2}$. Table 4 summarizes the performances of some representative oxide-based electrocatalysts.

\section{Transition metal carbides and nitrides}

\section{Carbides}

Owing to the s- and p-orbitals of neighboring $\mathrm{C}$ atoms, the $\mathrm{d}$ orbitals of metals in transition metal carbides are broadened and exhibit a Pt-like d band center, making the carbides show noble-metal-like physiochemical properties. As a result, carbides have been regarded as excellent HER electrocatalysts due to their metallic electronic structures, high conductivity, and earth abundance [111-116]. Tuning the phase and engineering the mesostructure can significantly enhance the activity. Baek et al. [117] constructed a metastable $\alpha-\mathrm{MoC}_{1-x}$ with highly ordered mesopores (MMC) from a nanocasting strategy using silica as the hard template. The DFT calculation showed that the $\alpha-\mathrm{MoC}_{1-x}$ had a stronger affinity to $\mathrm{OH}^{*}$ species and could favor the water dissociation during HER compared with hexagonal $\beta-\mathrm{Mo}_{2} \mathrm{C}$ (Fig. 12a). Besides, the unique mesoporous morphology of MMC provided a higher surface area and abundant active sites for HER. Due to the facilitated water dissociation and effective proton transfer of MMC, the Pt/MMC electro- catalyst exhibited high HER performance, which was superior to commercial Pt/C (Fig. 12b). Dopants can also optimize the adsorption of intermediates of carbides. Han et al. [118] doped nitrogen into WC nanoarrays on carbon fiber paper via a CVD process using $\mathrm{WO}_{3}$ nanoarrays as the substrate and melamine as the nitrogen source. Theoretical calculations demonstrated that the $\mathrm{N}$ dopants downshifted the density of $5 \mathrm{~d}$ states of $\mathrm{W}$ in $\mathrm{N}-\mathrm{WC}$ compared with that of WC. As a result, the affinity between $\mathrm{H}$ and catalytic sites became weaker, which led to an enhanced intrinsic activity. In addition, the morphology of the catalyst not only enlarged the exposure of active sites, but also accelerated the gas releasing. As a result, the as-prepared catalyst only required $190 \mathrm{mV}$ to reach $200 \mathrm{~mA} \mathrm{~cm}^{-2}$. Karuppannan et al. [119] fabricated a nitrogen and fluorine-doped carbon-encapsulated $\mathrm{Fe} / \mathrm{Fe}_{3}$ $\mathrm{C}\left(\mathrm{NFC@Fe} / \mathrm{Fe}_{3} \mathrm{C}\right)$ electrocatalyst by the carbonization and acid etching of a Fe-poly(aniline-fluoroaniline) copolymer, in which the carbide sites synergistically interacted with $\mathrm{F}$ - and $\mathrm{N}$-doped carbon and promoted the adsorption and reduction of oxygen on the ORR catalytic sites. Electrochemical tests showed that NFC@Fe/ $/ \mathrm{Fe}_{3} \mathrm{C}-9$ exhibited a higher $E_{1 / 2}$ value than commercial $\mathrm{Pt} / \mathrm{C}$ with an excellent durability in alkaline electrolyte. Moreover, NFC@Fe/ $\mathrm{Fe}_{3} \mathrm{C}-9$ exhibited high methanol tolerance in both acidic and alkaline electrolytes.

Constructing hybrids with heterostructures can facilitate the reactions of carbides [120]. Lu et al. [121] syn-

Table 4 Comparison of the performances of transition metal phosphide-based electrocatalysts for different applications

\begin{tabular}{|c|c|c|c|c|c|}
\hline Catalyst & Substrate & $\begin{array}{l}\text { Electrolyte } \\
\text { /reaction }\end{array}$ & $\begin{array}{l}\text { Overpotential } \\
(\mathrm{mV}) @ \mathrm{~mA} \mathrm{~cm}\end{array}$ & $\begin{array}{c}\text { Tafel slope } \\
\left(\mathrm{mV} \mathrm{decade}^{-1}\right)\end{array}$ & $\begin{array}{c}\text { Stability } \\
\left(\mathrm{mA} \mathrm{cm}^{-2} @ \mathrm{~h}\right)\end{array}$ \\
\hline CoP-Doped MOF [97] & Carbon Fiber paper & $1.0 \mathrm{~mol} \mathrm{~L}^{-1} \mathrm{KOH} / \mathrm{HER}$ & $34 @ 10$ & 56 & 2000 cycles \\
\hline MoP@NCHSs-900 [98] & GCE & $1.0 \mathrm{~mol} \mathrm{~L}^{-1} \mathrm{KOH} / \mathrm{HER}$ & 92@10 & 62 & 5000 cycles \\
\hline $\mathrm{Ni}_{2} \mathrm{P}$ nanoarray $[99]$ & $\mathrm{Ni}$ foam & $1.0 \mathrm{~mol} \mathrm{~L}^{-1} \mathrm{KOH} / \mathrm{HER}$ & 306@1000 & 76 & 5000 cycles \\
\hline $\mathrm{NiPS}_{3} / \mathrm{Ni}_{2} \mathrm{P}$ NSs $[100]$ & GCE & $1.0 \mathrm{~mol} \mathrm{~L}^{-1} \mathrm{KOH} / \mathrm{HER}$ & 85@10 & 82 & $10 @ 12$ \\
\hline Strained $\mathrm{FeP}_{2}[101]$ & Ni foam & $1.0 \mathrm{~mol} \mathrm{~L}^{-1} \mathrm{KOH} / \mathrm{OER}$ & 240@10 & 56 & \\
\hline NiCoP@NC NA/NF [103] & $\mathrm{Ni}$ foam & $1.0 \mathrm{~mol} \mathrm{~L}^{-1} \mathrm{KOH} / \mathrm{OER}$ & 305@50 & 70.5 & 10@15 \\
\hline NiCoP@NC NA/NF [103] & $\mathrm{Ni}$ foam & $1.0 \mathrm{~mol} \mathrm{~L}^{-1} \mathrm{KOH} / \mathrm{HER}$ & $37 @ 10$ & 53.9 & 35@22 \\
\hline Ultrathin NiCoP NSs [104] & $\mathrm{Ni}$ foam & $1.0 \mathrm{~mol} \mathrm{~L}^{-1} \mathrm{KOH} / \mathrm{OER}$ & 245@10 & 59.2 & 5000 cycles \\
\hline Ultrathin NiCoP NSs [104] & $\mathrm{Ni}$ foam & $1.0 \mathrm{~mol} \mathrm{~L}^{-1} \mathrm{KOH} / \mathrm{HER}$ & 34.3@10 & 49.9 & 5000 cycles \\
\hline Cr-doped FeNi-P/NCN [105] & Glassy carbon & $1.0 \mathrm{~mol} \mathrm{~L}^{-1} \mathrm{KOH} / \mathrm{OER}$ & 240@10 & 72.36 & 1000 cycles \\
\hline Cr-doped FeNi-P/NCN [105] & Glassy carbon & $1.0 \mathrm{~mol} \mathrm{~L}^{-1} \mathrm{KOH} / \mathrm{HER}$ & 190@10 & 68.51 & 1000 cycles \\
\hline $\mathrm{WS}_{2} / \mathrm{Ni}_{5} \mathrm{P}_{4}-\mathrm{Ni}_{2} \mathrm{P}$ [107] & Ni foam & $0.5 \mathrm{~mol} \mathrm{~L}^{-1} \mathrm{H}_{2} \mathrm{SO}_{4} / \mathrm{HER}$ & 94@10 & 74 & 1000 cycles \\
\hline V-CoP@a-CeO 2 [108] & Carbon cloth & $1.0 \mathrm{~mol} \mathrm{~L}^{-1} \mathrm{KOH} / \mathrm{OER}$ & 225@10 & 58 & 20@40 \\
\hline V-CoP@a-CeO 2 [108] & Carbon cloth & $1.0 \mathrm{~mol} \mathrm{~L}^{-1} \mathrm{KOH} / \mathrm{HER}$ & 68@10 & 48.1 & 20@60 \\
\hline CoP NS/CNTs [110] & GCE & $1.0 \mathrm{~mol} \mathrm{~L}^{-1} \mathrm{KOH} / \mathrm{HER}$ & 68@10 & 57 & $10 @ 24$ \\
\hline
\end{tabular}

GCE: glassy carbon electrode. 

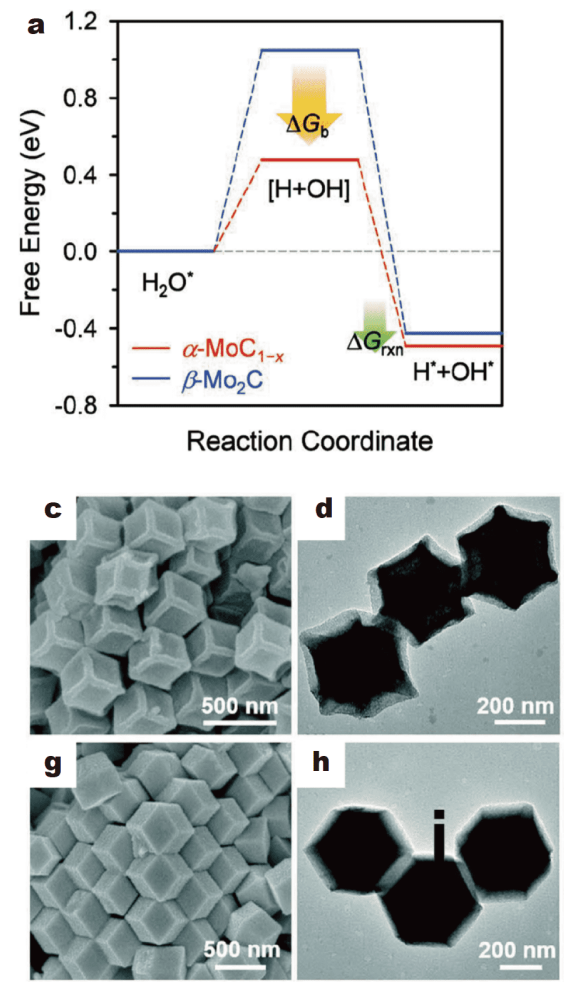
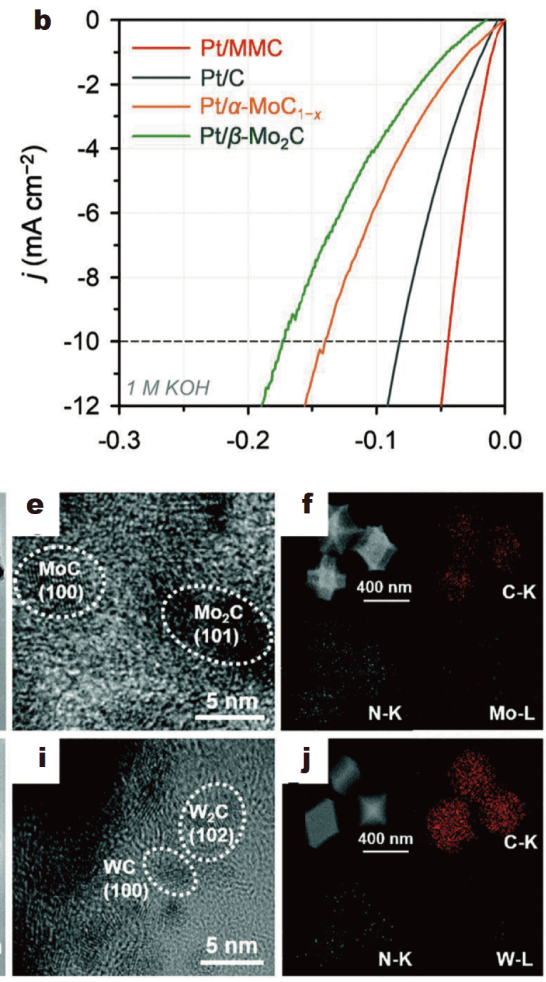

Figure 12 (a) Free energy profiles of water dissociation on different carbides, (b) HER LSV curves of different catalysts. Reprinted with permission [117]. Copyright 2019, Wiley. Field emission scanning electron microscopy (FESEM), TEM, HRTEM images and elemental mapping of (c-f) MoC$\mathrm{Mo}_{2} \mathrm{C} / \mathrm{PNCD}$ and $(\mathrm{g}-\mathrm{j}) \mathrm{WC}-\mathrm{W}_{2} \mathrm{C} / \mathrm{PNCD}$. Reprinted with permission [121]. Copyright 2019, Wiley.

thesized well-dispersed carbide nanocrystals trapped in porous $\mathrm{N}$-doped carbon dodecahedra ( $\mathrm{MC}-\mathrm{M}_{2} \mathrm{C} / \mathrm{PNCDs}$ ) for HER via pyrolysis of $\mathrm{Mo} / \mathrm{W}$ contained ZIF-8. The TEM images showed that the porous carbon frameworks enfolded the ultrafine carbide nanocrystals with a mixed phase of $\mathrm{MC}$ and $\mathrm{M}_{2} \mathrm{C}$ (Fig. 12c-j). Owing to the unique compositions and morphology, the catalysts exhibited much higher ESCAs and more active sites than the singlephase carbide, which was beneficial to the diffusion of the electrolyte. And the strong coupling between $\mathrm{N}$-doped carbon and carbides facilitated the electron transfer. Besides, the interaction between $\mathrm{MC}$ and $\mathrm{M}_{2} \mathrm{C}$ favored the reaction pathways by optimizing the adsorption for reactants. As a result, both $\mathrm{MoC}-\mathrm{Mo}_{2} \mathrm{C} / \mathrm{PNCD}$ and WC$\mathrm{W}_{2} \mathrm{C} / \mathrm{PNCD}$ exhibited enhanced HER activity compared with single-phased carbides. Li et al. [122] developed a metal-organic coordination precursor-assisted strategy for synthesizing porous molybdenum-contained carbon nanomaterials (mC-Mo). Dopamine hydrochloride was applied to induce the self-assembly of Mo-based nanocrystalline and silica was chosen as the hard template. The $\mathrm{Mo}_{2} \mathrm{C}$ and $\mathrm{Mo}_{2} \mathrm{~N}$ nanocrystallines were well confined in the as-prepared mesoporous materials, which showed a much higher surface area compared with nonmesoporous materials. Due to the mesoporous structure, the exposed active sites were significantly increased, which led to stronger mass and charge transfer properties. Besides, the interaction between $\mathrm{Mo}_{2} \mathrm{C}$ and $\mathrm{Mo}_{2} \mathrm{~N}$ induced a synergistic effect and provided a novel $\mathrm{Mo}^{\sigma+}$ site, which was highly active for HER. The mC-Mo electrocatalyst outperformed commercial $\mathrm{Pt} / \mathrm{C}$ in alkaline $\mathrm{HER}$ at high current densities. Li et al. [123] synthesized novel $\mathrm{N}$ doped carbon nanofibers that contained $\mathrm{Ni}$ and $\mathrm{Mo}_{2} \mathrm{C}$ nanoparticles ( $\left.\mathrm{Ni} / \mathrm{Mo}_{2} \mathrm{C}-\mathrm{NCNFs}\right)$ via a facile electrospinning method combined with a post-synthesis carbonization. Combining the electrospinning and carbonization process, the $\mathrm{Ni}$ and $\mathrm{Mo}_{2} \mathrm{C}$ nanocrystallines were well dispersed and strongly coupled in the carbon framework. Owing to the structural and composite properties, the electron/mass transfer capability and the exposure of active sites were favored. Moreover, the strong coupling between $\mathrm{Ni}$ and $\mathrm{Mo}_{2} \mathrm{C}$ induced electron transfer from $\mathrm{Ni}$ to $\mathrm{Mo}_{2} \mathrm{C}$. As a result, the adsorption of $\mathrm{H}$ on $\mathrm{Ni}$ and $\mathrm{Mo}_{2} \mathrm{C}$ was simultaneously optimized during $\mathrm{HER}$, and the water dissociation at $\mathrm{Ni}$ sites was also favored. On the other hand, the metal-carbide interaction 
induced an upshifted Ni d-band center and therefore the affinity between $\mathrm{OH}^{-}$and $\mathrm{Ni}$ was enhanced during OER. The $\mathrm{Ni} / \mathrm{Mo}_{2} \mathrm{C}-\mathrm{NCNF}$ showed a high overall water splitting performance (a cell voltage of $1.64 \mathrm{~V}$ to reach $10 \mathrm{~mA} \mathrm{~cm}^{-2}$ ).

\section{Nitrides}

Transition metal nitrides are novel metallic electrocatalysts with unique physiochemical and electronic properties [124-128]. Owing to the neighboring $\mathrm{N}$ atoms, the d-electron density of metals is increased and the contraction of the d-band center occurs, which induces that the nitrides show a similar electronic structure with Pt-group metals [124]. In addition, nitrides show high electron transfer ability and stability during the reaction [24]. Panda et al. [129] synthesized cubical $\mathrm{CuN}_{3}$ by the nitridation of copper acetate, which efficiently catalyzed HER, OER, and overall water splitting. Notably, water molecules could easily attack the coordinatively unsaturated copper sites in $\mathrm{CuN}_{3}$ and be deprotonated, which induced the formation of oxo-bridged copper sites and a $\mathrm{CuO}$ shell. Additionally, lots of vacancies and $\mathrm{CuO}$ $(\mathrm{H})$ structure with defects were generated through oxidative potentials (Fig. 13a, b). The strong collaborative effect between the amorphous overlayer and $\mathrm{CuN}_{3}$ and the defected structure helped to optimize the adsorption of the intermediates during OER. And metallic $\mathrm{Cu}$ enriched $\mathrm{CuO}$ surface favored the HER pathways. Consequently, the electrolyzer assembled by $\mathrm{CuN}_{3}$ showed a voltage of $1.62 \mathrm{~V}$ at $10 \mathrm{~mA} \mathrm{~cm}^{-2}$ with 10 -day stability. The carbon support can alter the adsorption of the intermediates on nitrides. Miao et al. [130] prepared an hMoN/BCNT nanomaterial, where hexagonal MoN nanoparticles were well encapsulated in B,N-codoped CNTs (BNCNTs) (Fig. 13c, d). They postmodified the Mo-based polyoxometalates, which were reduced by hexamethylenetetramine (HMT) with ammonia gas in the BNCNT. A large number of MoN NSs spread over the nanotubes (BNCNTs), which helped to expose abundant active sites and enhanced the electron transfer. The DFT calculations
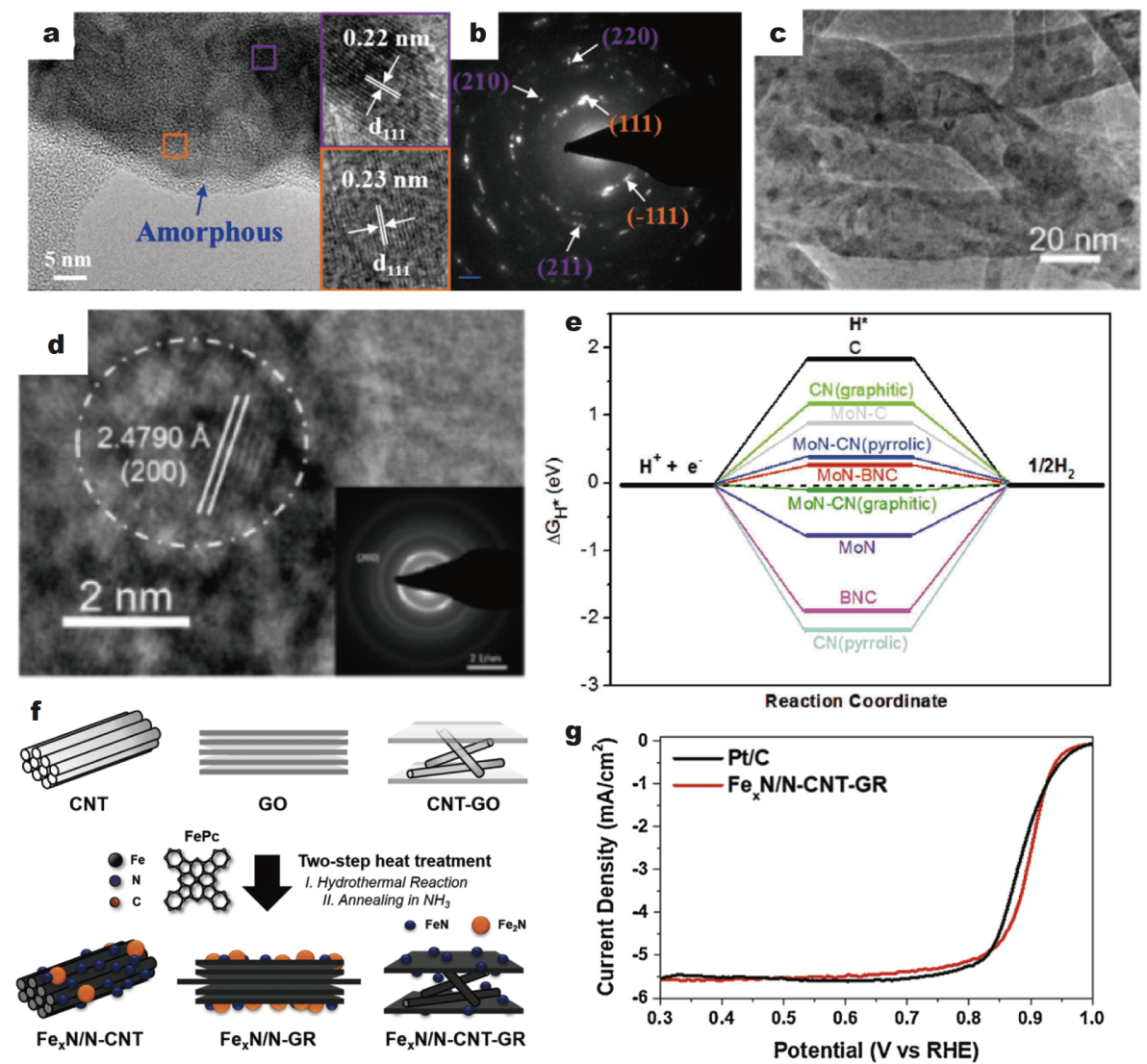

Figure 13 (a) HRTEM images and (b) SAED pattern of $\mathrm{Cu}_{3} \mathrm{~N}$ post-OER. Reprinted with permission [129]. Copyright 2019, American Chemical Society. (c, d) TEM and HRTEM images of h-MoN@BNCNT, (e) free energy of hydrogen adsorption on different samples. Reprinted with permission [130]. Copyright 2019, Wiley. (f) Schematic illustration of preparation of $\mathrm{Fe}_{x} \mathrm{~N} / \mathrm{N}-\mathrm{CNT}-\mathrm{GR}$ and (g) ORR polarization curves of Fe ${ }_{x} \mathrm{~N} / \mathrm{N}-\mathrm{CNT}-\mathrm{GR}$ and $\mathrm{Pt} / \mathrm{C}$. Reprinted with permission [131]. Copyright 2020, Elsevier. 
showed that different carbon layers on $\operatorname{MoN}(001)$ led to different hydrogen adsorption ability: both N-doped/B,Ncodoped graphene and pristine $\mathrm{MoN}(001)$ showed either too strong or too weak $\mathrm{H}$ adsorption. However, assembling N-doped/B,N-codoped carbon onto $\mathrm{MoN}(001)$ could optimize both the adsorption and desorption of hydrogen on the catalysts (Fig. 13e). Moreover, the electron transfer between different composites $(\mathrm{MoN} \rightarrow \mathrm{C} \rightarrow \mathrm{N})$ induced the carbon atoms to be new active sites for HER. Noh et al. [131] loaded $\mathrm{Fe}_{x} \mathrm{~N}$ nanoparticles in N-doped CNT-graphene $\left(\mathrm{Fe}_{x} \mathrm{~N} / \mathrm{N}-\mathrm{CNT}-\mathrm{GR}\right)$ through a hydrothermal process followed by annealing. Numerous small N-rich FeN nanoparticles were confined by the anchoring and defect sites of carbon support (Fig. 13f). The synergistic effect of $\mathrm{Fe}_{x} \mathrm{~N}(\mathrm{M}=\mathrm{Fe}, \mathrm{Co})$ nanoparticles and support created ORR sites with superior durability. Moreover, the $3 \mathrm{D}$ porous structure significantly facilitated the oxygen diffusion. Experimental results demonstrated that the $\mathrm{Fe}_{x} \mathrm{~N} / \mathrm{N}-\mathrm{CNT}-\mathrm{GR}$ catalyst showed an enhanced ORR activity with a halfwave potential of $0.89 \mathrm{~V} v s$. RHE comparable to commercial Pt/C in alkaline electrolyte (Fig. 13g).

Interface engineering has also been applied to design nitride-based electrocatalysts [132]. Wang et al. [133] engineered a copper-nickel nitride loaded on carbon fiber cloth $\left(\mathrm{Cu}_{1} \mathrm{Ni}_{2}-\mathrm{N} / \mathrm{CFC}\right)$ via annealing $\mathrm{CuNi}-\mathrm{LDH}$ precursor in ammonia. The as-prepared $\mathrm{Cu}_{1} \mathrm{Ni}_{2}-\mathrm{N} / \mathrm{CFC}$ ex- hibited a highly open and interconnected nanostructure, which simultaneously improved the mass and charge transfer (Fig. 14a-c). The controlled lattice arrangement between $\mathrm{Cu}_{4} \mathrm{~N}$ and $\mathrm{Ni}_{3} \mathrm{~N}$ contributed to increasing the HER active sites. The DOS showed that the $\mathrm{Cu}_{1} \mathrm{Ni}_{2}-\mathrm{N}$ was metallic and the d-band center of $\mathrm{Cu}_{4} \mathrm{~N}-\mathrm{Ni}_{3} \mathrm{~N}$ was downshifted, which optimized the adsorption of reaction intermediates. Besides, the surface hydroxide species generated during the reaction could serve as the OER active sites. When using hydrazine aqueous solution as the electrolyte, the electrolyzer based on $\mathrm{Cu}_{1} \mathrm{Ni}_{2}-\mathrm{N} / \mathrm{CFC}$ required a voltage of $0.24 \mathrm{~V}$ at $10 \mathrm{~mA} \mathrm{~cm}^{-2}$ with over $75-\mathrm{h}$ stability. As Lai et al. [134] reported, strong-interacted $\mathrm{NiCoN} / \mathrm{C}$ hybrid nanocages were prepared via nitridation of chemically etched ZIF-67. The as-prepared material presented a high ECSA and reduced electron transfer resistance. The DFT calculations demonstrated that the interaction between $\mathrm{C}$-sites in carbon layer helped to stabilize the Co and Ni sites, weaken the overbinding of the intermediates and promote the electron transfer (Fig. 14d). Moreover, the (Ni, Co)-N-bonding induced fast electron transfer and promoted the transformation of $\mathrm{Co}^{2+} \rightarrow \mathrm{Co}^{0}$, which was considered as an ideal site for water adsorption and splitting. Dong et al. [135] designed a V-Ni based nitride with 3D hierarchical heterostructure $\left(\mathrm{VN} @ \mathrm{Ni}_{3} \mathrm{~N}-\mathrm{Ni} / \mathrm{CC}\right)$ via in-situ nitridation of $\mathrm{V}-\mathrm{Ni}-\mathrm{O}$ precursors anchored on carbon cloth. The 3D hierarchical
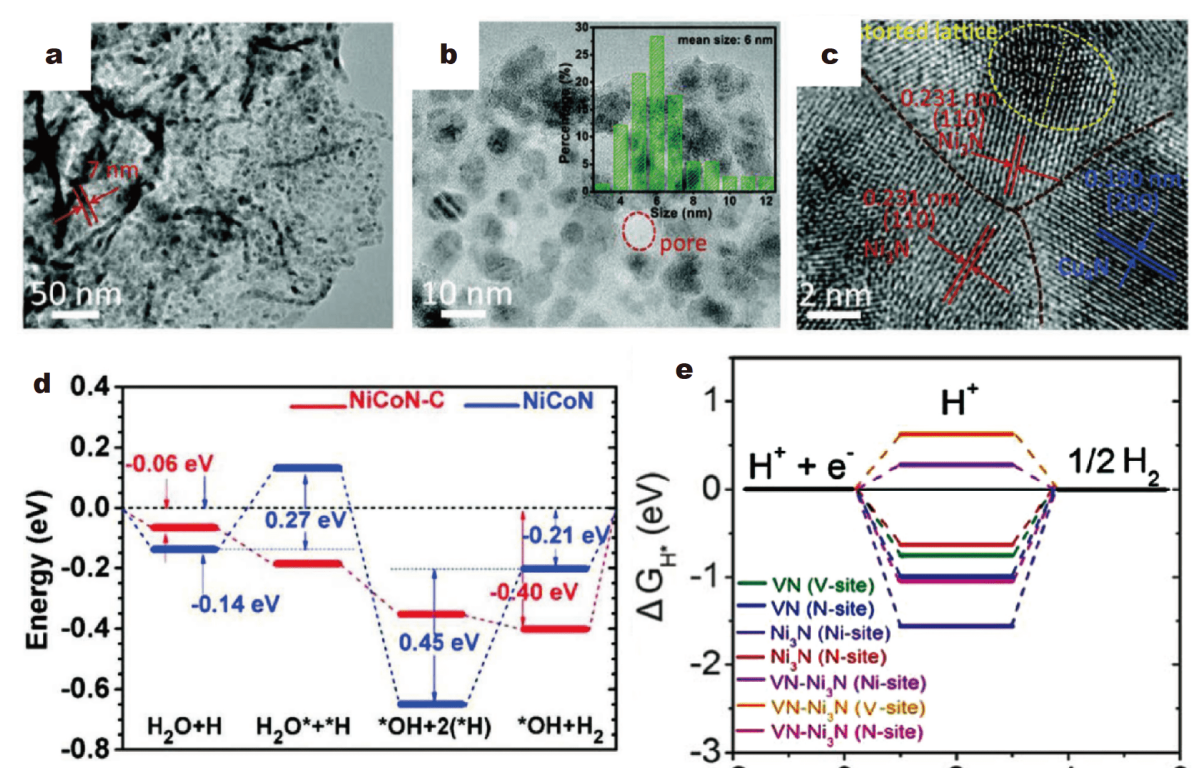

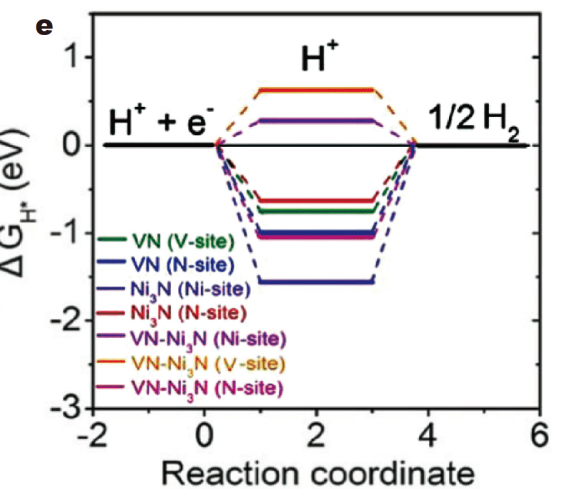

Figure 14 (a,b) TEM and (c) HRTEM images of $\mathrm{Cu}_{1} \mathrm{Ni}_{2}$-N/CFC. Reprinted with permission [133]. Copyright 2019, Wiley. (d) Alkaline HER free energies on different catalyst surfaces. Reprinted with permission [134]. Copyright 2019, Wiley. (e) HER free energy profile on tdifferent systems. Reprinted with permission [135]. Copyright 2019, American Chemical Society. 
nanostructure of the material helped to expose more active sites, promote the interaction between the electrode and electrolyte, and favor the release of the formed gas. The Ni $2 p$ binding energy exhibited a positive shift, indicating a strong electron interaction in $\mathrm{VN} @ \mathrm{Ni}_{3} \mathrm{~N}-\mathrm{Ni}$, which significantly optimized the adsorption and desorption of $\mathrm{H}^{*}$ : the $\Delta G_{\mathrm{H}}{ }^{*}$ of $\mathrm{Ni}$-site in $\mathrm{VN} @ \mathrm{Ni}_{3} \mathrm{~N}$ was much lowered, and therefore served as an excellent HER site (Fig. 14e). As a result, VN@ $\mathrm{Ni}_{3} \mathrm{~N}-\mathrm{Ni}$ showed a high catalytic performance with 8,23 , and $32 \mathrm{mV}$ onset potentials in $1.0 \mathrm{~mol} \mathrm{~L}^{-1} \mathrm{KOH}, \quad 1.0 \mathrm{~mol} \mathrm{~L}^{-1} \mathrm{PBS}$ and $0.5 \mathrm{~mol} \mathrm{~L}^{-1} \mathrm{H}_{2} \mathrm{SO}_{4}$, respectively. Table 5 summarizes the performances of some representative oxide-based electrocatalysts.

\section{CONCLUSIONS AND PERSPECTIVES}

From the discussions above, a large number of transitionmetal-compound-based nanomaterials have been designed and fabricated for electrocatalytic HER, OER and ORR in recent two years. And many of them have shown promising prospects in replacing noble metal-based catalysts for sustainable energy conversion and storage. To promote the development of electrocatalysts, various strategies have been proposed and applied in fabricating novel electrocatalysts, such as improving the ECSA to expose more catalytic sites, inducing electron redistribu- tion in the surface sites to modify the physiochemical properties of catalysts, increasing the intrinsic activity of active sites via tuning the composite/structure and optimizing the adsorption/desorption property of the intermediates, and reducing the resistance to favor the electron transfer during the reaction. As a result, some of the novel TMC-based nanomaterials can even outperform the noble metal-based electrocatalysts.

However, there are still some critical issues to be solved for further development and actual commercialization of TMC-based electrocatalysts: 1) the next-generation sustainable electrochemical energy conversion devices usually involve multi-reactions to simultaneously participate on the anode and cathode. For example, water electrolysis devices require simultaneous HER and OER, while zinc-air batteries require efficient OER and ORR performances on the anode. Therefore, more efforts are needed to develop novel catalysts with multi-functions and further improve the activities and stability to meet the industrialization requirements. 2) During the electrochemical reaction process, the high overpotential and the acid/alkaline electrolytes create a corrosive environment, which could induce strong reconstruction on the surface sites (including the composition, valence state, and phase change). However, most of the simulative crystalline structures in the theoretical calculations are

Table 5 Comparison of the performances of transition metal carbide/nitride-based electrocatalysts for different applications

\begin{tabular}{|c|c|c|c|c|c|}
\hline Catalyst & Substrate & $\begin{array}{l}\text { Electrolyte } \\
\text { /reaction }\end{array}$ & $\begin{array}{l}\text { Overpotential } \\
(\mathrm{mV}) @ \mathrm{~mA} \mathrm{~cm}{ }^{-2}\end{array}$ & $\begin{array}{c}\text { Tafel slope } \\
\left(\mathrm{mV} \mathrm{decade}^{-1}\right)\end{array}$ & $\begin{array}{c}\text { Stability } \\
\left(\mathrm{mA} \mathrm{cm} \mathrm{cm}^{-2} @ \mathrm{~h}\right)\end{array}$ \\
\hline $\mathrm{Co}-\mathrm{NC} @ \mathrm{Mo}_{2} \mathrm{C}[112]$ & GCE & $1.0 \mathrm{~mol} \mathrm{~L}^{-1} \mathrm{KOH} / \mathrm{HER}$ & 99@10 & 65 & 1000 cycles \\
\hline $\mathrm{Fe} / \mathrm{Fe}_{5} \mathrm{C}_{2} @ \mathrm{~N}$-doped carbon [113] & RRDE & $0.1 \mathrm{~mol} \mathrm{~L}^{-1} \mathrm{KOH} / \mathrm{ORR}$ & $E_{1 / 2}=0.85 \mathrm{~V}$ & 57 & 5000 cycles \\
\hline $\mathrm{Mo}_{2} \mathrm{CT}_{x}$ nanomeshs $[114]$ & $\mathrm{Ni}$ foam & $1.0 \mathrm{~mol} \mathrm{~L}^{-1} \mathrm{KOH} / \mathrm{OER}$ & 180@10 & 66 & $1.9 \mathrm{~V} @ 16$ \\
\hline $\mathrm{Mo}_{2} \mathrm{C} / \mathrm{VC}$ heterojunction [115] & Glassy carbon & $0.5 \mathrm{~mol} \mathrm{~L}^{-1} \mathrm{H}_{2} \mathrm{SO}_{4} / \mathrm{HER}$ & 122@10 & 43.8 & 10000 cycles \\
\hline $\mathrm{MoC}-\mathrm{Mo}_{2} \mathrm{C} / \mathrm{PNCDs}[121]$ & Carbon fiber paper & $1.0 \mathrm{~mol} \mathrm{~L}^{-1} \mathrm{KOH} / \mathrm{HER}$ & 121@10 & 60 & 10@20 \\
\hline $\mathrm{WC}-\mathrm{W}_{2} \mathrm{C} / \mathrm{PNCDs}[121]$ & Carbon fiber paper & $1.0 \mathrm{~mol} \mathrm{~L}^{-1} \mathrm{KOH} / \mathrm{HER}$ & 101@10 & 90 & 10@24 \\
\hline $\mathrm{mC}-\mathrm{Mo}-850$ [122] & $\mathrm{RDE}$ & $1.0 \mathrm{~mol} \mathrm{~L}^{-1} \mathrm{KOH} / \mathrm{HER}$ & 173@10 & 55 & 10/50/100@16 \\
\hline $\mathrm{Ni} / \mathrm{Mo}_{2} \mathrm{C}-\mathrm{NCNFs}[123]$ & $\mathrm{RDE}$ & $1.0 \mathrm{~mol} \mathrm{~L}^{-1} \mathrm{KOH} / \mathrm{HER}$ & 143@10 & 57.8 & 10@100 \\
\hline $\mathrm{Ni} / \mathrm{Mo}_{2} \mathrm{C}$-NCNFs [123] & $\mathrm{RDE}$ & $1.0 \mathrm{~mol} \mathrm{~L}^{-1} \mathrm{KOH} / \mathrm{OER}$ & 288@10 & 78.4 & 10@100 \\
\hline NiNS [125] & Glassy carbon & $1.0 \mathrm{~mol} \mathrm{~L}^{-1} \mathrm{KOH} / \mathrm{HER}$ & 197@100 & 58.8 & 5000 cycles \\
\hline $\mathrm{Ni}_{3} \mathrm{~N} / \mathrm{VN}[126]$ & $\mathrm{Ni}$ foam & $1.0 \mathrm{~mol} \mathrm{~L}^{-1} \mathrm{KOH} / \mathrm{HER}$ & $56 @ 10$ & 47 & 10@16 \\
\hline $\mathrm{FeNi}_{3} \mathrm{~N} / \mathrm{NG}[127]$ & RRDE & $1.0 \mathrm{~mol} \mathrm{~L}^{-1} \mathrm{KOH} / \mathrm{ORR}$ & $E_{1 / 2}=0.79 \mathrm{~V}$ & 78.8 & \\
\hline Cobalt vanadium nitride [128] & Carbon cloth & $1.0 \mathrm{~mol} \mathrm{~L}^{-1} \mathrm{KOH} / \mathrm{HER}$ & 118@10 & 73.6 & 1.56 V@20 \\
\hline $\mathrm{Cu}_{3} \mathrm{~N} / \mathrm{NF}[129]$ & $\mathrm{Ni}$ foam & $1.0 \mathrm{~mol} \mathrm{~L}^{-1} \mathrm{KOH} / \mathrm{OER}$ & 286@10 & 118.5 & 10@14 \\
\hline $\mathrm{Cu}_{3} \mathrm{~N} / \mathrm{NF}[129]$ & $\mathrm{Ni}$ foam & $1.0 \mathrm{~mol} \mathrm{~L}^{-1} \mathrm{KOH} / \mathrm{HER}$ & 118@10 & 122 & 10@14 \\
\hline h-MoN@BNCNT [130] & Glassy carbon & $0.5 \mathrm{~mol} \mathrm{~L}^{-1} \mathrm{H}_{2} \mathrm{SO}_{4} / \mathrm{HER}$ & 78@10 & 46 & 10@24 \\
\hline $\mathrm{NiCoN} / \mathrm{C}[134]$ & Carbon cloth & $1.0 \mathrm{~mol} \mathrm{~L}^{-1} \mathrm{KOH} / \mathrm{HER}$ & 103@10 & & 1000 cycles \\
\hline $\mathrm{VN} @ \mathrm{Ni}_{3} \mathrm{~N}-\mathrm{Ni} / \mathrm{CC}[135]$ & Carbon cloth & $1.0 \mathrm{~mol} \mathrm{~L}^{-1} \mathrm{KOH} / \mathrm{HER}$ & $57 @ 10$ & 40 & 3000 cycles \\
\hline
\end{tabular}


ideal models, which are based on the ex-situ characterizations such as XRD, HERTM and XPS. Therefore, there is still a gap between the theoretical and actual active sites, which makes it difficult to precisely predict the catalyst performance in the actual electrochemical test using the DFT calculation results. Hence, it is necessary to involve in-situ characterizations into the research and clarify the actual physicochemical properties of the active sites during the reaction. And it is clear that combining theoretical calculations and in-situ characterizations can greatly contribute to understanding the effect of active sites on the reaction performance and summarizing the structure-performance relationship. In the very recent years, this strategy has been more and more frequently applied in the electrocatalytic research, and the reported in-situ characterizations include XRD, XANES, Raman and infrared spectra [136-138]. 3) Currently, most of the TMC-based nanomaterials are prepared via a hydro/solvothermal method followed by annealing at a high temperature to increase the crystallinity. Especially, for sulfides, phosphides, nitrides and selenides, the sources of $\mathrm{S}, \mathrm{P}, \mathrm{N}$ and Se are usually toxic and may cause environmental concerns. Moreover, most of the current instruments for the preparation of nanomaterials are still laboratory level and it is difficult for the yield to reach a kilogram level. To realize the future commercialization of these TMC-based catalysts, it is necessary to develop facile preparation methods with massive amount producing ability. 4) Except the self-supported materials, most of the electrocatalysts have to be loaded onto the electrode using polymer binders to ensure strong-enough attachment during long-term operation [139]. However, the use of binders will significantly increase the cost (e.g., the price of Nafion solution (5 wt.\% in mixture of lower aliphatic alcohols and water) is ca. $250 \mathrm{USD} / 25 \mathrm{~mL}$ ) and cover the surface of the electrocatalysts, which would inhibit the exposure of active sites. Meanwhile, the conductivity will also be affected by the binder and the contact gap between the catalysts and the electrode. Therefore, further development of self-supported electrodes should help to lower the cost and enlarge the amount of active sites and conductivity. 5) Most of the current studies about TMCbased oxygen electrocatalysts are usually tested in alkaline electrolytes, as the acid environment with high overpotential will greatly corrode or dissolve the nanomaterials. It is therefore necessary to design and construct new composites or heterostructures to increase both the activity and stability of electrocatalysts in a wide $\mathrm{pH}$ range.

Therefore it is believed that further improvement of TMC-based electrocatalysts can be achieved from the inspirations of recent advances with deep understanding of the fundamental mechanisms and rational design of the composite and structure, which can help to replace the noble metal-based electrocatalysts and explore candidates for electrochemical energy devices.

Received 29 April 2020; accepted 2 July 2020;

published online 10 September 2020

1 Chen M, Xiao J, Hua W, et al. A cation and anion dual doping strategy for the elevation of titanium redox potential for highpower sodium-ion batteries. Angew Chem Int Ed, 2020, 59: 12076-12083

2 Wang H, Tang Q, Chen Z, et al. Recent advances on silica-based nanostructures in photocatalysis. Sci China Mater, 2020, 63: 2189-2205

3 Wang Y, Li Y, Wang Z, et al. Reticular chemistry in electrochemical carbon dioxide reduction. Sci China Mater, 2020, 63: 1113-1141

4 Dou S, Wang X, Wang S. Rational design of transition metalbased materials for highly efficient electrocatalysis. Small Methods, 2019, 3: 1800211

5 Li R, Lu Y, Lei K, et al. Resumption of the discharged $\mathrm{Li}-\mathrm{AgVO}_{3}$ primary batteries for rechargeable $\mathrm{Li}-\mathrm{O}_{2}$ batteries. Acta Chim Sin, 2017, 75: 199-205

6 Sun J, Guo L, Sun X, et al. One-dimensional nanostructured pseudocapacitive materials: design, synthesis and applications in supercapacitors. Batteries Supercaps, 2019, 2: 820-841

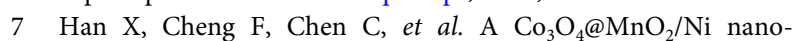
composite as a carbon- and binder-free cathode for rechargeable $\mathrm{Li}-\mathrm{O}_{2}$ batteries. Inorg Chem Front, 2016, 3: 866-871

8 Yu D, Li X, Xu J. Safety regulation of gel electrolytes in electrochemical energy storage devices. Sci China Mater, 2019, 62: 15561573

9 Zhu Y, Liu X, Jin S, et al. Anionic defect engineering of transition metal oxides for oxygen reduction and evolution reactions. J Mater Chem A, 2019, 7: 5875-5897

10 Seh ZW, Kibsgaard J, Dickens CF, et al. Combining theory and experiment in electrocatalysis: Insights into materials design. Science, 2017, 355: eaad4998

11 Huang $\mathrm{H}, \mathrm{Tu} \mathrm{S}$, Zeng C, et al. Macroscopic polarization enhancement promoting photo- and piezoelectric-induced charge separation and molecular oxygen activation. Angew Chem Int Ed, 2017, 56: 11860-11864

$12 \mathrm{Xu} \mathrm{N}, \mathrm{Li} \mathrm{X}, \mathrm{Li} \mathrm{H}$, et al. A novel composite (FMC) to serve as a durable 3D-clam-shaped bifunctional cathode catalyst for both primary and rechargeable zinc-air batteries. Sci Bull, 2017, 62: $1216-1226$

$13 \mathrm{Ni} \mathrm{B}, \mathrm{Wu} \mathrm{L}$, Chen $\mathrm{R}$, et al. Fe/Co-based nanoparticles encapsulated in heteroatom-doped carbon electrocatalysts for oxygen reduction reaction. Sci China Mater, 2016, 62: 1626-1641

14 Shi Y, Zhang B. Recent advances in transition metal phosphide nanomaterials: synthesis and applications in hydrogen evolution reaction. Chem Soc Rev, 2016, 45: 1529-1541

15 Pan Y, Zhang C, Lin Y, et al. Electrocatalyst engineering and structure-activity relationship in hydrogen evolution reaction: From nanostructures to single atoms. Sci China Mater, 2020, 63: 921-948

16 Sun T, Zhang G, Xu D, et al. Defect chemistry in 2D materials for 
electrocatalysis. Mater Today Energy, 2019, 12: 215-238

17 Wang J, Yue X, Yang Y, et al. Earth-abundant transition-metalbased bifunctional catalysts for overall electrochemical water splitting: A review. J Alloys Compd, 2020, 819: 153346

18 Ye G, Gong Y, Lin J, et al. Defects engineered monolayer $\mathrm{MoS}_{2}$ for improved hydrogen evolution reaction. Nano Lett, 2016, 16: 1097-1103

$19 \mathrm{Xu} \mathrm{L}$, Jiang $\mathrm{Q}$, Xiao Z, et al. Plasma-engraved $\mathrm{Co}_{3} \mathrm{O}_{4}$ nanosheets with oxygen vacancies and high surface area for the oxygen evolution reaction. Angew Chem, 2016, 128: 5363-5367

20 Wang H, Liu R, Li Y, et al. Durable and efficient hollow porous oxide spinel microspheres for oxygen reduction. Joule, 2018, 2 : 337-348

21 Zhou $\mathrm{H}, \mathrm{Yu}$ F, Sun J, et al. Highly active catalyst derived from a $3 \mathrm{D}$ foam of $\mathrm{Fe}\left(\mathrm{PO}_{3}\right)_{2} / \mathrm{Ni}_{2} \mathrm{P}$ for extremely efficient water oxidation. Proc Natl Acad Sci USA, 2017, 114: 5607-5611

22 Pei Y, Cheng Y, Chen J, et al. Recent developments of transition metal phosphides as catalysts in the energy conversion field. J Mater Chem A, 2018, 6: 23220-23243

23 Sun H, Yan Z, Liu F, et al. Self-supported transition-metal-based electrocatalysts for hydrogen and oxygen evolution. Adv Mater, 2020, 32: 1806326

24 Chen Z, Duan X, Wei W, et al. Recent advances in transition metal-based electrocatalysts for alkaline hydrogen evolution. J Mater Chem A, 2019, 7: 14971-15005

25 Zou X, Zhang Y. Noble metal-free hydrogen evolution catalysts for water splitting. Chem Soc Rev, 2015, 44: 5148-5180

26 Morales-Guio CG, Stern LA, Hu X. Nanostructured hydrotreating catalysts for electrochemical hydrogen evolution. Chem Soc Rev, 2014, 43: 6555-6569

27 Suen NT, Hung SF, Quan Q, et al. Electrocatalysis for the oxygen evolution reaction: recent development and future perspectives. Chem Soc Rev, 2017, 46: 337-365

28 Anantharaj S, Ede SR, Sakthikumar K, et al. Recent trends and perspectives in electrochemical water splitting with an emphasis on sulfide, selenide, and phosphide catalysts of $\mathrm{Fe}, \mathrm{Co}$, and Ni: A Review. ACS Catal, 2016, 6: 8069-8097

29 Ge X, Sumboja A, Wuu D, et al. Oxygen reduction in alkaline media: from mechanisms to recent advances of catalysts. ACS Catal, 2015, 5: 4643-4667

30 Wang Y, Li J, Wei Z. Transition-metal-oxide-based catalysts for the oxygen reduction reaction. J Mater Chem A, 2018, 6: 81948209

31 Skúlason E, Tripkovic V, Björketun ME, et al. Modeling the electrochemical hydrogen oxidation and evolution reactions on the basis of density functional theory calculations. J Phys Chem C, 2010, 114: 18182-18197

32 Diaz-Morales O, Ledezma-Yanez I, Koper MTM, et al. Guidelines for the rational design of Ni-based double hydroxide electrocatalysts for the oxygen evolution reaction. ACS Catal, 2015, 5: 5380-5387

33 Nørskov JK, Rossmeisl J, Logadottir A, et al. Origin of the overpotential for oxygen reduction at a fuel-cell cathode. J Phys Chem B, 2004, 108: 17886-17892

34 Zhang T, Wu MY, Yan DY, et al. Engineering oxygen vacancy on $\mathrm{NiO}$ nanorod arrays for alkaline hydrogen evolution. Nano Energy, 2018, 43: 103-109

35 Xue Y, Sun S, Wang Q, et al. Transition metal oxide-based oxygen reduction reaction electrocatalysts for energy conversion systems with aqueous electrolytes. J Mater Chem A, 2018, 6:
10595-10626

36 Teng Y, Wang XD, Liao JF, et al. Atomically thin defect-rich FeMn-O hybrid nanosheets as high efficient electrocatalyst for water oxidation. Adv Funct Mater, 2018, 28: 1802463

37 Fu G, Yan X, Chen Y, et al. Boosting bifunctional oxygen electrocatalysis with 3D graphene aerogel-supported $\mathrm{Ni} / \mathrm{MnO}$ particles. Adv Mater, 2018, 30: 1704609

38 Zhou Y, Sun S, Xi S, et al. Superexchange effects on oxygen reduction activity of edge-sharing $\left[\mathrm{Co}_{x} \mathrm{Mn}_{1-x} \mathrm{O}_{6}\right]$ octahedra in spinel oxide. Adv Mater, 2018, 30: 1705407

39 Wei C, Sun S, Mandler D, et al. Approaches for measuring the surface areas of metal oxide electrocatalysts for determining their intrinsic electrocatalytic activity. Chem Soc Rev, 2019, 48: 25182534

40 Liu Q, Hu Z, Chen M, et al. Recent progress of layered transition metal oxide cathodes for sodium-ion batteries. Small, 2019, 15: 1805381

41 Han X, He G, He Y, et al. Engineering catalytic active sites on cobalt oxide surface for enhanced oxygen electrocatalysis. Adv Energy Mater, 2018, 8: 1702222

42 Lai F, Feng J, Ye X, et al. Energy level engineering in transitionmetal doped spinel-structured nanosheets for efficient overall water splitting. J Mater Chem A, 2019, 7: 827-833

43 Peng S, Han X, Li L, et al. Electronic and defective engineering of electrospun $\mathrm{CaMnO}_{3}$ nanotubes for enhanced oxygen electrocatalysis in rechargeable zinc-air batteries. Adv Energy Mater, 2018, 8: 1800612

44 Li X, Wei J, Li Q, et al. Nitrogen-doped cobalt oxide nanostructures derived from cobalt-alanine complexes for high-performance oxygen evolution reactions. Adv Funct Mater, 2018, 28: 1800886

45 Ling T, Zhang T, Ge B, et al. Well-dispersed nickel- and zinctailored electronic structure of a transition metal oxide for highly active alkaline hydrogen evolution reaction. Adv Mater, 2019, 31: 1807771

46 Zhao Y, Zhang J, Wu W, et al. Cobalt-doped $\mathrm{MnO}_{2}$ ultrathin nanosheets with abundant oxygen vacancies supported on functionalized carbon nanofibers for efficient oxygen evolution. Nano Energy, 2018, 54: 129-137

47 Liu J, Ji Y, Nai J, et al. Ultrathin amorphous cobalt-vanadium hydr(oxy)oxide catalysts for the oxygen evolution reaction. Energy Environ Sci, 2018, 11: 1736-1741

48 Chen ZJ, Cao GX, Gan LY, et al. Highly dispersed platinum on honeycomb-likeNiO@Ni film as a synergistic electrocatalyst for the hydrogen evolution reaction. ACS Catal, 2018, 8: 8866-8872

49 Zheng P, Zhang Y, Dai Z, et al. Constructing multifunctional heterostructure of $\mathrm{Fe}_{2} \mathrm{O}_{3} @ \mathrm{Ni}_{3} \mathrm{Se}_{4}$ nanotubes. Small, 2018, 14: 1704065

50 Yan Z, Sun H, Chen X, et al. Anion insertion enhanced electrodeposition of robust metal hydroxide/oxide electrodes for oxygen evolution. Nat Commun, 2018, 9: 2373

51 Zhang $\mathrm{X}, \mathrm{Li}$ J, Yang $\mathrm{Y}$, et al. $\mathrm{Co}_{3} \mathrm{O}_{4} / \mathrm{Fe}_{0.33} \mathrm{Co}_{0.66} \mathrm{P}$ interface nanowire for enhancing water oxidation catalysis at high current density. Adv Mater, 2018, 30: 1803551

$52 \mathrm{Yu} \mathrm{ZY}$, Lang CC, Gao MR, et al. Ni-Mo-O nanorod-derived composite catalysts for efficient alkaline water-to-hydrogen conversion via urea electrolysis. Energy Environ Sci, 2018, 11: 18901897

53 An L, Feng J, Zhang Y, et al. Epitaxial heterogeneous interfaces on $\mathrm{N}-\mathrm{NiMoO}_{4} / \mathrm{NiS}_{2}$ nanowires/nanosheets to boost hydrogen and 
oxygen production for overall water splitting. Adv Funct Mater, 2019, 29: 1805298

$54 \mathrm{Xu} \mathrm{H}$, Shi ZX, Tong YX, et al. Porous microrod arrays constructed by carbon-confined $\mathrm{NiCo@} \mathrm{NiCoO}_{2}$ core@shell nanoparticles as efficient electrocatalysts for oxygen evolution. Adv Mater, 2018, 30: 1705442

55 Duan Y, Sun S, Sun Y, et al. Mastering surface reconstruction of metastable spinel oxides for better water oxidation. Adv Mater, 2019, 31: 1807898

56 Yan Z, Xiao J, Lai W, et al. Nickel sulfide nanocrystals on nitrogen-doped porous carbon nanotubes with high-efficiency electrocatalysis for room-temperature sodium-sulfur batteries. Nat Commun, 2019, 10: 4793

57 Yan Y, Xia BY, Xu Z, et al. Recent development of molybdenum sulfides as advanced electrocatalysts for hydrogen evolution reaction. ACS Catal, 2014, 4: 1693-1705

58 Yilmaz G, Yang T, Du Y, et al. Stimulated electrocatalytic hydrogen evolution activity of MOF-derived $\mathrm{MoS}_{2}$ basal domains via charge injection through surface functionalization and heteroatom doping. Adv Sci, 2019, 6: 1900140

59 Zhu J, Wang ZC, Dai H, et al. Boundary activated hydrogen evolution reaction on monolayer $\mathrm{MoS}_{2}$. Nat Commun, 2019, 10: 1348

60 Zhou G, Shan Y, Wang L, et al. Photoinduced semiconductormetal transition in ultrathin troilite $\mathrm{FeS}$ nanosheets to trigger efficient hydrogen evolution. Nat Commun, 2019, 10: 399

61 Zhong J, Wu T, Wu Q, et al. $\mathrm{N}$ - and S- co-doped graphene sheetencapsulated $\mathrm{Co}_{9} \mathrm{~S}_{8}$ nanomaterials as excellent electrocatalysts for the oxygen evolution reaction. J Power Sources, 2019, 417: 90-98

62 Guo Y, Park T, Yi JW, et al. Nanoarchitectonics for transitionmetal-sulfide-based electrocatalysts for water splitting. Adv Mater, 2019, 31: 1807134

63 Kuang $\mathrm{P}, \mathrm{He} \mathrm{M}$, Zou H, et al. 0D/3D $\mathrm{MoS}_{2}-\mathrm{NiS}_{2} / \mathrm{N}$-doped graphene foam composite for efficient overall water splitting. Appl Catal B-Environ, 2019, 254: 15-25

64 Joo J, Kim T, Lee J, et al. Morphology-controlled metal sulfides and phosphides for electrochemical water splitting. Adv Mater, 2019, 31: 1806682

65 Dong J, Zhang FQ, Yang Y, et al. (003)-Facet-exposed $\mathrm{Ni}_{3} \mathrm{~S}_{2}$ nanoporous thin films on nickel foil for efficient water splitting. Appl Catal B-Environ, 2019, 243: 693-702

$66 \mathrm{Li} \mathrm{B}$, Jiang L, Li X, et al. Controllable synthesis of nanosized amorphous $\mathrm{MoS}_{x}$ using temporally shaped femtosecond laser for highly efficient electrochemical hydrogen production. Adv Funct Mater, 2019, 29: 1806229

67 Yang $\mathrm{H}$, Wang B, Li H, et al. Trimetallic sulfide mesoporous nanospheres as superior electrocatalysts for rechargeable $\mathrm{Zn}$-air batteries. Adv Energy Mater, 2018, 8: 1801839

68 Kong D, Wang Y, Lim YV, et al. 3D hierarchical defect-rich $\mathrm{NiMo}_{3} \mathrm{~S}_{4}$ nanosheet arrays grown on carbon textiles for highperformance sodium-ion batteries and hydrogen evolution reaction. Nano Energy, 2018, 49: 460-470

$69 \mathrm{Qu} \mathrm{Y}$, Yang M, Chai J, et al. Facile synthesis of vanadium-doped $\mathrm{Ni}_{3} \mathrm{~S}_{2}$ nanowire arrays as active electrocatalyst for hydrogen evolution reaction. ACS Appl Mater Interfaces, 2017, 9: 59595967

70 Muthurasu A, Maruthapandian V, Kim HY. Metal-organic framework derived $\mathrm{Co}_{3} \mathrm{O}_{4} / \mathrm{MoS}_{2}$ heterostructure for efficient bifunctional electrocatalysts for oxygen evolution reaction and hydrogen evolution reaction. Appl Catal B-Environ, 2019, 248:
202-210

71 Liu $\mathrm{Y}$, Jiang $\mathrm{S}$, Li $\mathrm{S}$, et al. Interface engineering of $(\mathrm{Ni}$, $\mathrm{Fe}) \mathrm{S}_{2} @ \mathrm{MoS}_{2}$ heterostructures for synergetic electrochemical water splitting. Appl Catal B-Environ, 2019, 247: 107-114

72 Kim M, Anjum MAR, Lee M, et al. Activating $\mathrm{MoS}_{2}$ basal plane with $\mathrm{Ni}_{2} \mathrm{P}$ nanoparticles for Pt-like hydrogen evolution reaction in acidic media. Adv Funct Mater, 2019, 29: 1809151

73 Nguyen DC, Tran DT, Doan TLL, et al. Rational design of core@shell structured $\mathrm{CoS}_{x} @ \mathrm{Cu}_{2} \mathrm{MoS}_{4}$ hybridized $\mathrm{MoS}_{2} / \mathrm{N}$,S-codoped graphene as advanced electrocatalyst for water splitting and Zn-air battery. Adv Energy Mater, 2020, 10: 1903289

74 Han X, Zhang W, Ma X, et al. Identifying the activation of bimetallic sites in $\mathrm{NiCo}_{2} \mathrm{~S}_{4} @ g-\mathrm{C}_{3} \mathrm{~N}_{4}$-CNT hybrid electrocatalysts for synergistic oxygen reduction and evolution. Adv Mater, 2019, 31: 1808281

75 Cao $\mathrm{Y}$, Zheng $\mathrm{X}$, Zhang $\mathrm{H}$, et al. Interface engineering of $\mathrm{NiS}_{2} /$ $\mathrm{CoS}_{2}$ nanohybrids as bifunctional electrocatalysts for rechargeable solid state Zn-air battery. J Power Sources, 2019, 437: 226893

76 Lu H, Zhang Y, Huang Y, et al. Reaction packaging $\mathrm{CoSe}_{2}$ nanoparticles in $\mathrm{N}$-doped carbon polyhedra with bifunctionality for overall water splitting. ACS Appl Mater Interfaces, 2019, 11: 3372-3381

77 Dutta B, Wu Y, Chen J, et al. Partial surface selenization of cobalt sulfide microspheres for enhancing the hydrogen evolution reaction. ACS Catal, 2019, 9: 456-465

78 Zheng $\mathrm{X}$, Han $\mathrm{X}$, Cao $\mathrm{Y}$, et al. Identifying dense $\mathrm{NiSe}_{2} / \mathrm{CoSe}_{2}$ heterointerfaces coupled with surface high-valence bimetallic sites for synergistically enhanced oxygen electrocatalysis. Adv Mater, 2020, 32: 2000607

79 Zou Z, Wang X, Huang J, et al. An Fe-doped nickel selenide nanorod/nanosheet hierarchical array for efficient overall water splitting. J Mater Chem A, 2019, 7: 2233-2241

80 Ding J, Wang P, Ji S, et al. Mesoporous nickel selenide N-doped carbon as a robust electrocatalyst for overall water splitting. Electrochim Acta, 2019, 300: 93-101

81 Liu Y, Xu Y, Han Y, et al. Facile synthesis of $\mathrm{SnSe}_{2}$ nanoparticles supported on graphite nanosheets for improved sodium storage and hydrogen evolution. J Power Sources, 2019, 436: 226860

$82 \mathrm{Yu} \mathrm{J}, \mathrm{Li}$ WJ, Zhang $\mathrm{H}$, et al. Metallic $\mathrm{FePSe}_{3}$ nanoparticles anchored on $\mathrm{N}$-doped carbon framework for all-pH hydrogen evolution reaction. Nano Energy, 2019, 57: 222-229

83 Chen J, Pan A, Wang Y, et al. Hierarchical mesoporous $\mathrm{MoSe}_{2} @ \mathrm{CoSe} / \mathrm{N}$-doped carbon nanocomposite for sodium ion batteries and hydrogen evolution reaction applications. Energy Storage Mater, 2019, 21: 97-106

84 Shi X, Wang H, Kannan $\mathrm{P}$, et al. Rich-grain-boundary of $\mathrm{Ni}_{3} \mathrm{Se}_{2}$ nanowire arrays as multifunctional electrode for electrochemical energy storage and conversion applications. J Mater Chem A, 2019, 7: 3344-3352

85 Wang S, He P, Jia L, et al. Nanocoral-like composite of nickel selenide nanoparticles anchored on two-dimensional multilayered graphitic carbon nitride: A highly efficient electrocatalyst for oxygen evolution reaction. Appl Catal B-Environ, 2019, 243: 463-469

86 Wang X, He J, Yu B, et al. $\mathrm{CoSe}_{2}$ nanoparticles embedded MOFderived $\mathrm{Co}-\mathrm{N}-\mathrm{C}$ nanoflake arrays as efficient and stable electrocatalyst for hydrogen evolution reaction. Appl Catal B-Environ, 2019, 258: 117996

87 Chen $\mathrm{P}, \mathrm{Xu} \mathrm{K}$, Tao S, et al. Phase-transformation engineering in cobalt diselenide realizing enhanced catalytic activity for hydro- 
gen evolution in an alkaline medium. Adv Mater, 2016, 28: 75277532

88 Deng S, Ai C, Luo M, et al. Coupled biphase (1T-2H)-MoSe $\mathrm{C}_{2}$ on mold spore carbon for advanced hydrogen evolution reaction. Small, 2019, 15: 1901796

89 Deng S, Yang F, Zhang Q, et al. Phase modulation of (1T-2H)$\mathrm{MoSe}_{2} / \mathrm{TiC}-\mathrm{C}$ shell/core arrays via nitrogen doping for highly efficient hydrogen evolution reaction. Adv Mater, 2018, 30: 1802223

90 Zhang X, Zhang YY, Zhang Y, et al. Phase-controlled synthesis of $1 \mathrm{~T}-\mathrm{MoSe}_{2} / \mathrm{NiSe}$ heterostructure nanowire arrays via electronic injection for synergistically enhanced hydrogen evolution. Small Methods, 2019, 3: 1800317

91 Najafi L, Bellani S, Oropesa-Nuñez R, et al. Engineered $\mathrm{MoSe}_{2}$ based heterostructures for efficient electrochemical hydrogen evolution reaction. Adv Energy Mater, 2018, 8: 1703212

92 Zhao Y, Jin B, Zheng Y, et al. Charge state manipulation of cobalt selenide catalyst for overall seawater electrolysis. Adv Energy Mater, 2018, 8: 1801926

93 Yuan M, Dipazir S, Wang M, et al. Polyoxometalate-assisted formation of $\mathrm{CoSe} / \mathrm{MoSe}_{2}$ heterostructures with enhanced oxygen evolution activity. J Mater Chem A, 2019, 7: 3317-3326

94 Jing B, You S, Ma Y, et al. $\mathrm{Fe}_{3} \mathrm{Se}_{4} / \mathrm{FeSe}$ heterojunctions in cornstalk-derived N-doped carbon framework enhance charge transfer and cathodic oxygen reduction reaction to boost bioelectricity generation. Appl Catal B-Environ, 2019, 244: 465-474

95 Wang J, Zheng X, Cao Y, et al. Developing indium-based ternary spinel selenides for efficient solid flexible $\mathrm{Zn}$-air batteries and water splitting. ACS Appl Mater Interfaces, 2020, 12: 8115-8123

96 Zhu Y-, Xiao Y, Hua W-, et al. Manipulating layered P2@P3 integrated spinel structure evolution for high-performance sodium-ion batteries. Angew Chem Int Ed, 2020, 59: 9299-9304

97 Liu T, Li P, Yao N, et al. CoP-doped MOF-based electrocatalyst for $\mathrm{pH}$-universal hydrogen evolution reaction. Angew Chem Int Ed, 2019, 58: 4679-4684

98 Zhao D, Sun K, Cheong WC, et al. Synergistically interactive pyridinic-N-MoP sites: identified active centers for enhanced hydrogen evolution in alkaline solution. Angew Chem, 2020, 132: 9067-9075

99 Yu X, Yu ZY, Zhang XL, et al. "Superaerophobic" nickel phosphide nanoarray catalyst for efficient hydrogen evolution at ultrahigh current densities. J Am Chem Soc, 2019, 141: 7537-7543

100 Liang Q, Zhong L, Du C, et al. Interfacing epitaxial dinickel phosphide to 2D nickel thiophosphate nanosheets for boosting electrocatalytic water splitting. ACS Nano, 2019, 13: 7975-7984

101 Li G, Yang Q, Rao J, et al. In situ induction of strain in iron phosphide $\left(\mathrm{FeP}_{2}\right)$ catalyst for enhanced hydroxide adsorption and water oxidation. Adv Funct Mater, 2020, 30: 1907791

$102 \mathrm{Du} \mathrm{H}$, Xia L, Zhu S, et al. Al-doped $\mathrm{Ni}_{2} \mathrm{P}$ nanosheet array: a superior and durable electrocatalyst for alkaline hydrogen evolution. Chem Commun, 2018, 54: 2894-2897

103 Cao B, Cheng Y, Hu M, et al. Efficient and durable 3D selfsupported nitrogen-doped carbon-coupled nickel/cobalt phosphide electrodes: stoichiometric ratio regulated phase- and morphology-dependent overall water splitting performance. Adv Funct Mater, 2019, 29: 1906316

104 Lv X, Li X, Yang C, et al. Large-size, porous, ultrathin NiCoP nanosheets for efficient electro/photocatalytic water splitting. Adv Funct Mater, 2020, 30: 1910830

105 Wu Y, Tao X, Qing Y, et al. Cr-doped FeNi-P nanoparticles encapsulated into $\mathrm{N}$-doped carbon nanotube as a robust bifunctional catalyst for efficient overall water splitting. Adv Mater, 2019, 31: 1900178

106 Wang MQ, Ye C, Liu H, et al. Nanosized metal phosphides embedded in nitrogen-doped porous carbon nanofibers for enhanced hydrogen evolution at all $\mathrm{pH}$ values. Angew Chem Int Ed, 2018, 57: 1963-1967

107 Yu SH, Chen W, Wang H, et al. Highly stable tungsten disulfide supported on a self-standing nickel phosphide foam as a hybrid electrocatalyst for efficient electrolytic hydrogen evolution. Nano Energy, 2019, 55: 193-202

108 Yang L, Liu R, Jiao L. Electronic redistribution: Construction and modulation of interface engineering on CoP for enhancing overall water splitting. Adv Funct Mater, 2020, 30: 1909618

109 Boppella R, Tan J, Yang W, et al. Homologous CoP/NiCoP heterostructure on $\mathrm{N}$-doped carbon for highly efficient and $\mathrm{pH}$ universal hydrogen evolution electrocatalysis. Adv Funct Mater, 2019, 29: 1807976

110 Zhang Y, Wang Y, Wang T, et al. Heterostructure of 2D CoP nanosheets/1D carbon nanotubes to significantly boost the alkaline hydrogen evolution. Adv Mater Interfaces, 2020, 7: 1901302

111 Göhl D, Garg A, Paciok P, et al. Engineering stable electrocatalysts by synergistic stabilization between carbide cores and $\mathrm{Pt}$ shells. Nat Mater, 2020, 19: 287-291

112 Liang Q, Jin H, Wang Z, et al. Metal-organic frameworks derived reverse-encapsulation Co-NC@ $\mathrm{Mo}_{2} \mathrm{C}$ complex for efficient overall water splitting. Nano Energy, 2019, 57: 746-752

113 Song L, Wang T, Li L, et al. $\mathrm{Zn}_{3}\left[\mathrm{Fe}(\mathrm{CN})_{6}\right]_{2}$ derived $\mathrm{Fe} / \mathrm{Fe}_{5} \mathrm{C}_{2} @ \mathrm{~N}$ doped carbon as a highly effective oxygen reduction reaction catalyst for zinc-air battery. Appl Catal B-Environ, 2019, 244: 197-205

114 Kou Z, Zhang L, Ma Y, et al. 2D carbide nanomeshes and their assembling into 3D microflowers for efficient water splitting. Appl Catal B-Environ, 2019, 243: 678-685

115 Huang $\mathrm{C}$, Miao X, Pi C, et al. $\mathrm{Mo}_{2} \mathrm{C} / \mathrm{VC}$ heterojunction embedded in graphitic carbon network: An advanced electrocatalyst for hydrogen evolution. Nano Energy, 2019, 60: 520-526

116 Gao Q, Zhang W, Shi Z, et al. Structural design and electronic modulation of transition-metal-carbide electrocatalysts toward efficient hydrogen evolution. Adv Mater, 2019, 31: 1802880

117 Baek DS, Jung GY, Seo B, et al. Ordered mesoporous metastable $\alpha-\mathrm{MoC}_{1-x}$ with enhanced water dissociation capability for boosting alkaline hydrogen evolution activity. Adv Funct Mater, 2019, 29: 1901217

118 Han N, Yang KR, Lu Z, et al. Nitrogen-doped tungsten carbide nanoarray as an efficient bifunctional electrocatalyst for water splitting in acid. Nat Commun, 2018, 9: 924

119 Karuppannan M, Park JE, Bae HE, et al. A nitrogen and fluorine enriched $\mathrm{Fe} / \mathrm{Fe}_{3} \mathrm{C} @ \mathrm{C}$ oxygen reduction reaction electrocatalyst for anion/proton exchange membrane fuel cells. Nanoscale, 2020, 12 : 2542-2554

120 Lin $\mathrm{H}$, Zhang W, Shi Z, et al. Electrospinning hetero-nanofibers of $\mathrm{Fe}_{3} \mathrm{C}-\mathrm{Mo}_{2} \mathrm{C} /$ nitrogen-doped-carbon as efficient electrocatalysts for hydrogen evolution. ChemSusChem, 2017, 10: 2597-2604

121 Lu XF, Yu L, Zhang J, et al. Ultrafine dual-phased carbide nanocrystals confined in porous nitrogen-doped carbon dodecahedrons for efficient hydrogen evolution reaction. Adv Mater, 2019, 31: 1900699

122 Li S, Cheng C, Sagaltchik A, et al. Metal-organic precursor-derived mesoporous carbon spheres with homogeneously dis- 
tributed molybdenum carbide/nitride nanoparticles for efficient hydrogen evolution in alkaline media. Adv Funct Mater, 2019, 29: 1807419

123 Li M, Zhu Y, Wang $\mathrm{H}$, et al. Ni strongly coupled with $\mathrm{Mo}_{2} \mathrm{C}$ encapsulated in nitrogen-doped carbon nanofibers as robust bifunctional catalyst for overall water splitting. Adv Energy Mater, 2019, 9: 1803185

124 Peng X, Pi C, Zhang X, et al. Recent progress of transition metal nitrides for efficient electrocatalytic water splitting. Sustain Energy Fuels, 2019, 3: 366-381

125 Zhao Y, Jin B, Vasileff A, et al. Interfacial nickel nitride/sulfide as a bifunctional electrode for highly efficient overall water/seawater electrolysis. J Mater Chem A, 2019, 7: 8117-8121

Zhou P, Xing D, Liu Y, et al. Accelerated electrocatalytic hydrogen evolution on non-noble metal containing trinickel nitride by introduction of vanadium nitride. J Mater Chem A, 2019, 7: 5513-5521

127 Liu L, Yan F, Li K, et al. Ultrasmall $\mathrm{FeNi}_{3} \mathrm{~N}$ particles with an exposed active (110) surface anchored on nitrogen-doped graphene for multifunctional electrocatalysts. J Mater Chem A, 2019, 7: 1083-1091

128 Dutta S, Indra A, Feng Y, et al. Promoting electrocatalytic overall water splitting with nanohybrid of transition metal nitride-oxynitride. Appl Catal B-Environ, 2019, 241: 521-527

129 Panda C, Menezes PW, Zheng M, et al. In situ formation of nanostructured core-shell $\mathrm{Cu}_{3} \mathrm{~N}-\mathrm{CuO}$ to promote alkaline water electrolysis. ACS Energy Lett, 2019, 4: 747-754

130 Miao J, Lang Z, Zhang X, et al. Polyoxometalate-derived hexagonal molybdenum nitrides (MXenes) supported by boron, nitrogen codoped carbon nanotubes for efficient electrochemical hydrogen evolution from seawater. Adv Funct Mater, 2018, 28: 1805893

131 Noh WY, Lee JH, Lee JS. Nitrogen-doped carbon nanotubegraphene hybrid stabilizes $M_{x} N(M=F e, C o)$ nanoparticles for efficient oxygen reduction reaction. Appl Catal B-Environ, 2020, 268: 118415

132 Hou J, Sun Y, Li Z, et al. Electrical behavior and electron transfer modulation of nickel-copper nanoalloys confined in nickel-copper nitrides nanowires array encapsulated in nitrogen-doped carbon framework as robust bifunctional electrocatalyst for overall water splitting. Adv Funct Mater, 2018, 28: 1803278

133 Wang Z, Xu L, Huang F, et al. Copper-nickel nitride nanosheets as efficient bifunctional catalysts for hydrazine-assisted electrolytic hydrogen production. Adv Energy Mater, 2019, 9: 1900390

134 Lai J, Huang B, Chao Y, et al. Strongly coupled nickel-cobalt nitrides/carbon hybrid nanocages with Pt-like activity for hydrogen evolution catalysis. Adv Mater, 2019, 31: 1805541

135 Dong X, Yan H, Jiao Y, et al. 3D hierarchical V-Ni-based nitride heterostructure as a highly efficient $\mathrm{pH}$-universal electrocatalyst for the hydrogen evolution reaction. J Mater Chem A, 2019, 7: 15823-15830

136 Wang J, Kattel S, Hawxhurst CJ, et al. Enhancing activity and reducing cost for electrochemical reduction of $\mathrm{CO}_{2}$ by supporting palladium on metal carbides. Angew Chem Int Ed, 2019, 58: 6271-6275

137 Ortiz Peña N, Ihiawakrim D, Han M, et al. Morphological and structural evolution of $\mathrm{Co}_{3} \mathrm{O}_{4}$ nanoparticles revealed by in situ electrochemical transmission electron microscopy during electrocatalytic water oxidation. ACS Nano, 2019, 13: 11372-11381
Li X, Wang HY, Yang H, et al. In situ/operando characterization techniques to probe the electrochemical reactions for energy conversion. Small Methods, 2018, 2: 1700395

$139 \mathrm{Hu}$ Q, Li G, Liu X, et al. Superhydrophilic phytic-acid-doped conductive hydrogels as metal-free and binder-free electrocatalysts for efficient water oxidation. Angew Chem Int Ed, 2019, 58: $4318-4322$

Acknowledgements This work was supported by the National Natural Science Foundation of China (51804216 and 51972224), the Young Elite Scientists Sponsorship Program by CAST (2018QNRC001) and Tianjin Natural Science Foundation (17JCQNJC02100). Wang J acknowledges the support from China Postdoctoral Science Foundation (2019M661014).

Author contributions Wang J wrote the paper; Wang J and Zhang Z prepared the figures; Ding J, Zhong $C$ and Deng Y revised the manuscript; Han X and $\mathrm{Hu}$ W provided the overall concept and revised the manuscript. All authors participated in the discussion.

Conflict of interest The authors declare no conflict of interest.

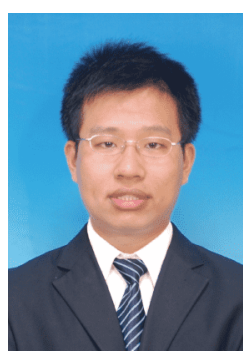

Xiaopeng Han is an associate professor in the School of Materials Science and Engineering at Tianjin University. He received his BSc from Tianjin University (2010) and $\mathrm{PhD}$ from Nankai University (2015), respectively. His current research interests focus on the synthesis and engineering of metal or metal-based functional materials for electrocatalysis and secondary high energy battery applications.

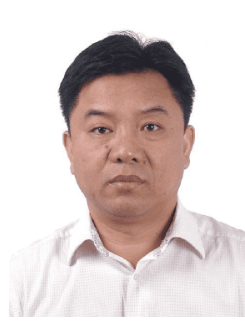

Wenbin $\mathbf{H u}$ is a professor in the Department of Materials Science \& Engineering, Tianjin University. He graduated from the Central South University with a BSc degree in 1988 . He received his MSc degree from Tianjin University in 1991, and $\mathrm{PhD}$ degree from the Central South University in 1994. His research interests focus on the design, synthesis and characterization of advanced nanomaterials for energy storage and conversion applications.

\section{微纳结构过渡金属化合物能源转化电催化剂研究 进展}

王嘉骏 ${ }^{1}$, 张昭 ${ }^{1}$, 丁佳 ${ }^{1}$, 钟澄 ${ }^{1}$, 邓意达 ${ }^{1}$, 韩晓鹏 ${ }^{1^{*}}$, 胡文彬 ${ }^{1,2^{*}}$

摘要 化石能源的快速消耗已导致日益严重的气候问题与能源危 机, 因此开发清洁绿色的可持续能源技术对人类社会的发展至关 重要. 电化学能源转化与存储器件目前受到广泛关注, 而开发高效 廉价的电催化剂则是该类技术发展的重中之重. 在多种电催化剂 中, 过渡金属化合物由于其储量丰富、性能优越而被广泛研究. 本 文综述了包括氧化物、硫化物、硒化物、磷化物、碳化物及氮化 物在内的微纳结构过渡金属化合物电催化剂的近期研究进展, 内 容包括各类化合物的可控制备方法、实际电催化应用(析氢、析氧 及氧还原)与相关反应机理; 同时讨论了该领域目前存在的挑战与 进一步的发展策略. 本文意在介绍过渡金属基电催化剂的最新进 展与研究前沿, 从而为进一步开发低成本、高性能的清洁能源电 催化剂提供参考与思路. 